\title{
Concentration-discharge relationships reflect chemostatic characteristics of US catchments
}

\author{
Sarah E. Godsey, ${ }^{1 *}$ James W. Kirchner, ${ }^{1,2,3}$ and David W. Clow ${ }^{4 \dagger}$ \\ ${ }^{1}$ Department of Earth and Planetary Science, 307 McCone Hall, University of California, Berkeley, CA 94720-4767, USA, 510-643-8559 \\ ${ }^{2}$ Swiss Federal Institute for Forest, Snow, and Landscape Research (WSL), Birmensdorf, Switzerland \\ ${ }^{3}$ Department of Environmental Sciences, Swiss Federal Institute of Technology (ETH), Zurich, Switzerland \\ ${ }^{4}$ U.S. Geological Survey, Water Resources Division, Denver Federal Center, MS 415, Box 25046, Denver, CO 80225 USA, 303-236-4882 x294
}

\begin{abstract}
:
Concentration-discharge relationships have been widely used as clues to the hydrochemical processes that control runoff chemistry. Here we examine concentration-discharge relationships for solutes produced primarily by mineral weathering in 59 geochemically diverse US catchments. We show that these catchments exhibit nearly chemostatic behaviour; their stream concentrations of weathering products such as $\mathrm{Ca}, \mathrm{Mg}, \mathrm{Na}$, and Si typically vary by factors of only 3 to 20 while discharge varies by several orders of magnitude. Similar patterns are observed at the inter-annual time scale. This behaviour implies that solute concentrations in stream water are not determined by simple dilution of a fixed solute flux by a variable flux of water, and that rates of solute production and/or mobilization must be nearly proportional to water fluxes, both on storm and inter-annual timescales. We compared these catchments' concentration-discharge relationships to the predictions of several simple hydrological and geochemical models. Most of these models can be forced to approximately fit the observed concentration-discharge relationships, but often only by assuming unrealistic or internally inconsistent parameter values. We propose a new model that also fits the data and may be more robust. We suggest possible tests of the new model for future studies. The relative stability of concentration under widely varying discharge may help make aquatic environments habitable. It also implies that fluxes of weathering solutes in streams, and thus fluxes of alkalinity to the oceans, are determined primarily by water fluxes. Thus, hydrology may be a major driver of the ocean-alkalinity feedback regulating climate change. Copyright (c) 2009 John Wiley \& Sons, Ltd.
\end{abstract}

KEY WORDS concentration-discharge; dissolved load; solute; chemical weathering; Hydrologic Benchmark Network; water quality; catchment; watershed

Received 27 August 2008; Accepted 19 February 2009

\section{INTRODUCTION}

Chemical weathering and solute transport are coupled with hydrology in catchments, and this coupling is reflected in the relationships between solute concentrations and stream discharge. Catchment hydrologists often study concentration-discharge relationships because the necessary data are frequently available and the initial analysis is straightforward. However, despite decades of work, there are still open questions about what concentration-discharge relationships can tell us about catchment behavior.

Concentrations of the major base cations and silica have generally been observed to decrease with discharge (Hem, 1948, 1985; Johnson et al., 1969 and references therein; Waylen, 1979; Walling and Webb, 1986; Clow and Drever, 1996). Typical concentration-discharge analyses have centered on mixing models of different source waters (e.g. event and pre-event water; old and new water; or soil water, groundwater and precipitation)

\footnotetext{
* Correspondence to: Sarah E. Godsey, Department of Earth and Planetary Science, 307 McCone Hall, University of California, Berkeley, CA 94720-4767, USA, 510-643-8559. E-mail: godseys@eps.berkeley.edu

${ }^{\dagger}$ The contribution of David W. Clow to this article was prepared as part of his official duties as a United States Federal Government employee.
}

inferred from the shape of the concentration-discharge relationship for different solutes (Johnson et al., 1969; Hall, 1970, 1971). In other studies, researchers have inferred the relative timing of mixing from hysteresis loops observed in concentration-discharge plots (Evans and Davies, 1998; Evans et al., 1999; House and Warwick, 1998; Hornberger et al., 2001; Chanat et al., 2002). Evans and Davies (1998) proposed that the form and direction of hysteresis loops could uniquely identify the rank order of end-member concentrations in a three end-member mixing scenario. However, Chanat et al. (2002) showed that even the small number of assumptions required for this identification are not always valid, and that when the assumptions are violated, hysteresis loops cannot definitively distinguish the relative concentrations of different end-members. Nonetheless, other characteristics of concentration-discharge relationships may provide insight into the coupling of chemical weathering and hydrological processes in catchments.

In this paper, we identify common features of concentration-discharge relationships across a range of hydrochemically distinct catchments with minimal human impacts, and discuss the implications of those features. We then compare several simple models against the 

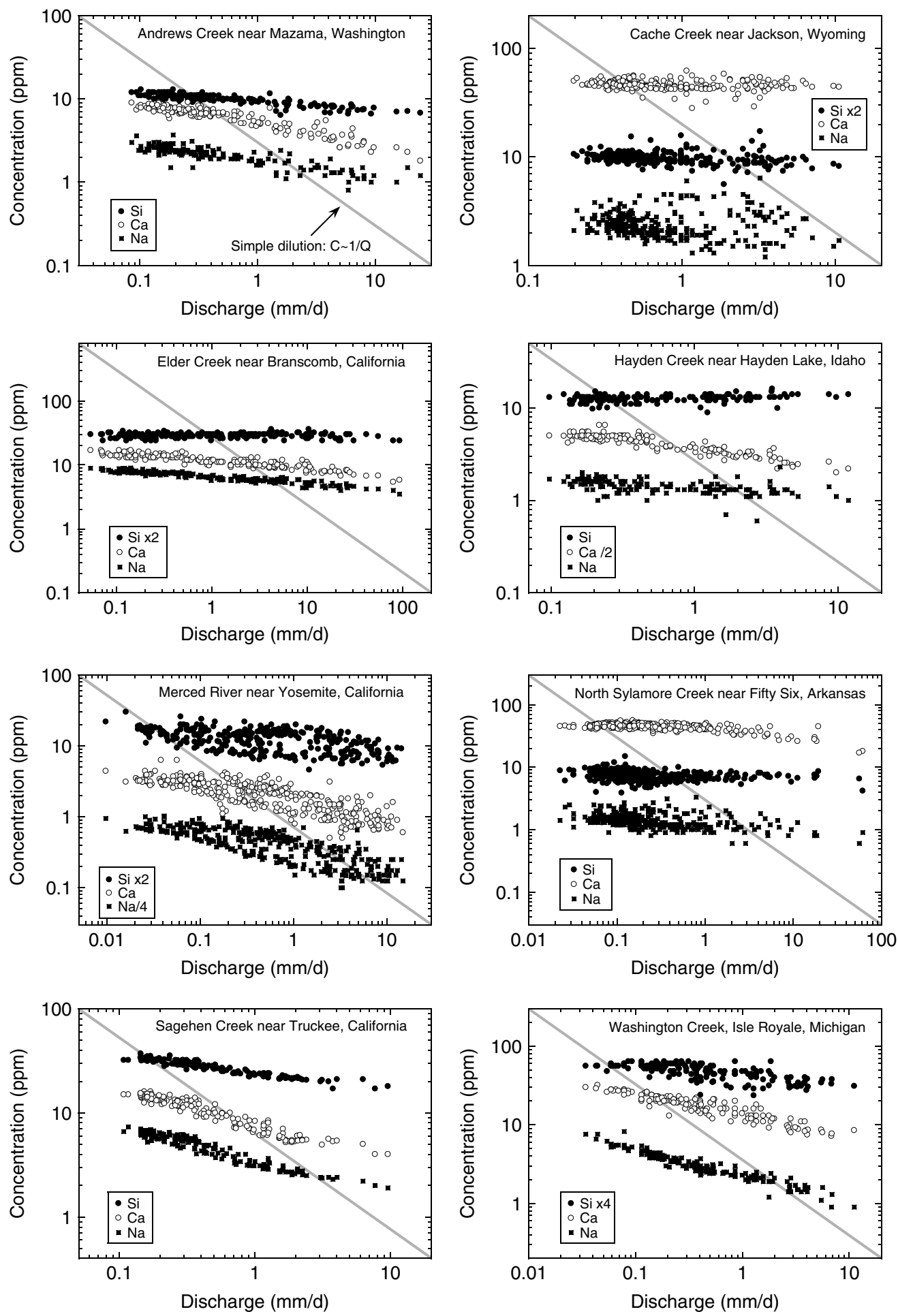

Figure 1. Concentration-discharge relationships for $\mathrm{Si}, \mathrm{Ca}$ and $\mathrm{Na}$ at eight Hydrologic Benchmark Network streams. Each plot has consistent axes (same number of $\log$ units for both concentration and discharge), so concentrations determined by dilution of fixed weathering fluxes would have the same slope as the grey diagonal lines shown (log-log slope of -1$)$. Instead, concentration-discharge relationships conform more closely to chemostatic behaviour (log-log slope near zero).

observed patterns in concentration-discharge relationships and evaluate whether their assumptions are generally valid across the study sites. Finally, we show that the concentration-discharge relationships observed in many catchments imply that changes in stream solute fluxes as a result of climatic forcing are, to first order, dependent upon changes in hydrology.

\section{OBSERVATIONS}

We plotted concentrations of the major weatheringderived cations ( $\mathrm{Mg}, \mathrm{Na}$ and $\mathrm{Ca}$ ) and dissolved silica (Si) against instantaneous discharge on logarithmic axes for 59 sites in the United States Geological Survey's (USGS) Hydrologic Benchmark Network (HBN) (e.g. 
Figure 1, discussed further below). The HBN was established in the mid-1960s to provide a long-term database to track changes in the flow and water quality of undisturbed streams and rivers, and to serve as a reference, or 'benchmark', for discerning natural from human-induced changes in river ecosystems (Leopold, 1962). Most HBN sites have more than 30 years of hydrochemical data, and water samples were typically collected five to seven times per year using standard USGS methods (Wilde et al., 1998). The HBN is the only nationwide network of environmental monitoring sites that tracks the health of rivers draining mid-sized, undisturbed basins in the United States. The sites are located throughout the country, usually in National Parks, National Forests or reserves where minimal human influence is expected. Site characteristics compiled from USGS circulars (Mast and Turk, 1999a,b; Clark et al., 2000; Mast and Clow, 2000) are summarized in Table I. Drainage areas range from $6 \cdot 1$ to $5196 \mathrm{~km}^{2}$ $\left(\right.$ median $\left.=146 \mathrm{~km}^{2}\right)$ and average annual runoff varies from 0.7 to $400 \mathrm{~cm} /$ year (median $=40 \mathrm{~cm} /$ year). Many environments in the United States are represented, including tropical forests, tundra and eight sites with $<10-\mathrm{cm}$ average annual runoff, which include arid and semi-arid grasslands, shrublands and semi-desert areas. Most catchments are forested, but several of the basins have substantial alpine and grassland areas. The 59 sites encompass a wide range of lithologic settings (Table I). Solute concentrations in precipitation are not available at all sites for the entire period of record, so the reported concentrations are not corrected by the precipitation chemistry. Stream concentrations of $\mathrm{Ca}, \mathrm{Na}$ and $\mathrm{Mg}$ are at least 10 to 100 times higher than available mean precipitation concentrations. Si concentrations in rainfall are not typically measured, but are normally orders of magnitude lower than Si concentrations in streamflow.

We plotted the concentrations of each of the major weathering-derived solutes against instantaneous discharge. We then calculated simple linear regression statistics for each of the sites and solutes, and, using Student's $\mathrm{t}$ test, determined whether the best-fit slope was significantly different from reference slopes of zero and -1 (whose meaning is discussed in detail below). We identified sites with non-linear relationships between log concentration and log discharge by examining the residuals of the linear fit. Most of the catchments in the HBN exhibit much less variability in concentrations than in discharge (Figure 1). Figure 1 shows concentration as a function of discharge on logarithmic axes, with the same number of log units shown on each axis to facilitate a visual comparison of the relative variability of concentration and discharge. For example, between high flow and low flow, concentrations at Elder Creek increase by factors of $3(\mathrm{Ca}$ and $\mathrm{Mg}), 2.6(\mathrm{Na})$ and $1.5(\mathrm{Si})$, as discharge changes by a factor of $\sim 6000$. Although not plotted in Figure 1, similar relationships also hold for $\mathrm{Mg}$ across the HBN sites.

As seen in Figure 1, concentration-discharge plots are often linear on logarithmic axes, indicating that there is a power-law relationship between concentration, $C$, and discharge, $Q$ (i.e. $C=\mathrm{a} Q^{\mathrm{b}}$, where a and $\mathrm{b}$ are constants). The exponent in this power-law relationship (or equivalently, the slope of the concentration-discharge relationship on logarithmic axes) has a physical interpretation. A slope of zero would indicate that the catchment behaves chemostatically, that is, the system keeps concentrations constant as discharge varies. A slope of -1 , on the other hand, would indicate that concentrations vary inversely with discharge, as might be expected if dilution were the dominant process controlling concentrations, such that approximately constant fluxes of solutes were diluted by variable fluxes of water.

Power-law concentration-discharge relationships like those shown in Figure 1 can be usefully summarized by their $\log -\log$ slopes. The best-fit $\log (C)-\log (Q)$ slopes for each solute can then be compared across all 59 of the HBN sites (Figure 2) and can be compared to reference slopes of zero (chemostatic behaviour) and -1 (dilution). Uncertainty in the best-fit slope of \pm 1 standard error (SE) is indicated by error bars, which are shown if they are larger than the plotting symbols. Across all sites, slopes are generally slightly less than zero. The means of the best-fit $\log$-log concentration-discharge slopes vary between approximately -0.05 and -0.15 (SE of the slope $\sim 0.01-0.02$ ) for each of the solutes. No slope is within two SEs of -1 and only four (Na), six $(\mathrm{Mg})$, eight $(\mathrm{Ca})$ and $14(\mathrm{Si})$ of the 59 sites have slopes within two SEs of zero. Slopes across all sites and solutes are strikingly similar. In general, $\mathrm{Si}$ slopes are closer to zero than the slopes of the other solutes. With few exceptions (discussed below), nearly all of the concentration-discharge relationships in this study can be described by power-law relationships with small negative exponents. The data in Figure 2 show that most catchments behave almost chemostatically for chemical weathering products such as $\mathrm{Ca}, \mathrm{Mg}, \mathrm{Na}$ and $\mathrm{Si}$.

Although this near-chemostatic behaviour is common, examination of residual plots for all sites and solutes reveals that the best fits for up to $10 \%$ of the sites may not be power-law. Such sites are marked by open circles in Figure 2 and the plotted slope of the linear fit only provides a general sense of the concentration-discharge relationship for these sites. We also calculated the ratio of the standard deviation of log discharge to log concentration for all sites and solutes (not shown) to quantify the relative variability of discharge and concentration without making any assumptions about the form of the concentration-discharge relationship. Only Upper Three Runs, SC had $\mathrm{Ca}$ and $\mathrm{Mg}$ concentrations that were more variable than its discharge, and only Castle Creek, SD and Dismal River, NE had more variable Na concentrations. No sites had Si concentrations that were more variable than discharge. The ratio of the standard deviations of log discharge to log concentration ranged from just below 1 to $21 \cdot 5$, with the median ratio equal to $4 \cdot 1$ (Ca), 4.0 (Mg and $\mathrm{Na}$ ), and 5.3 ( $\mathrm{Si}$ ). These observations reinforce the inference drawn from the shallow powerlaw slopes, namely that these catchments behave almost 


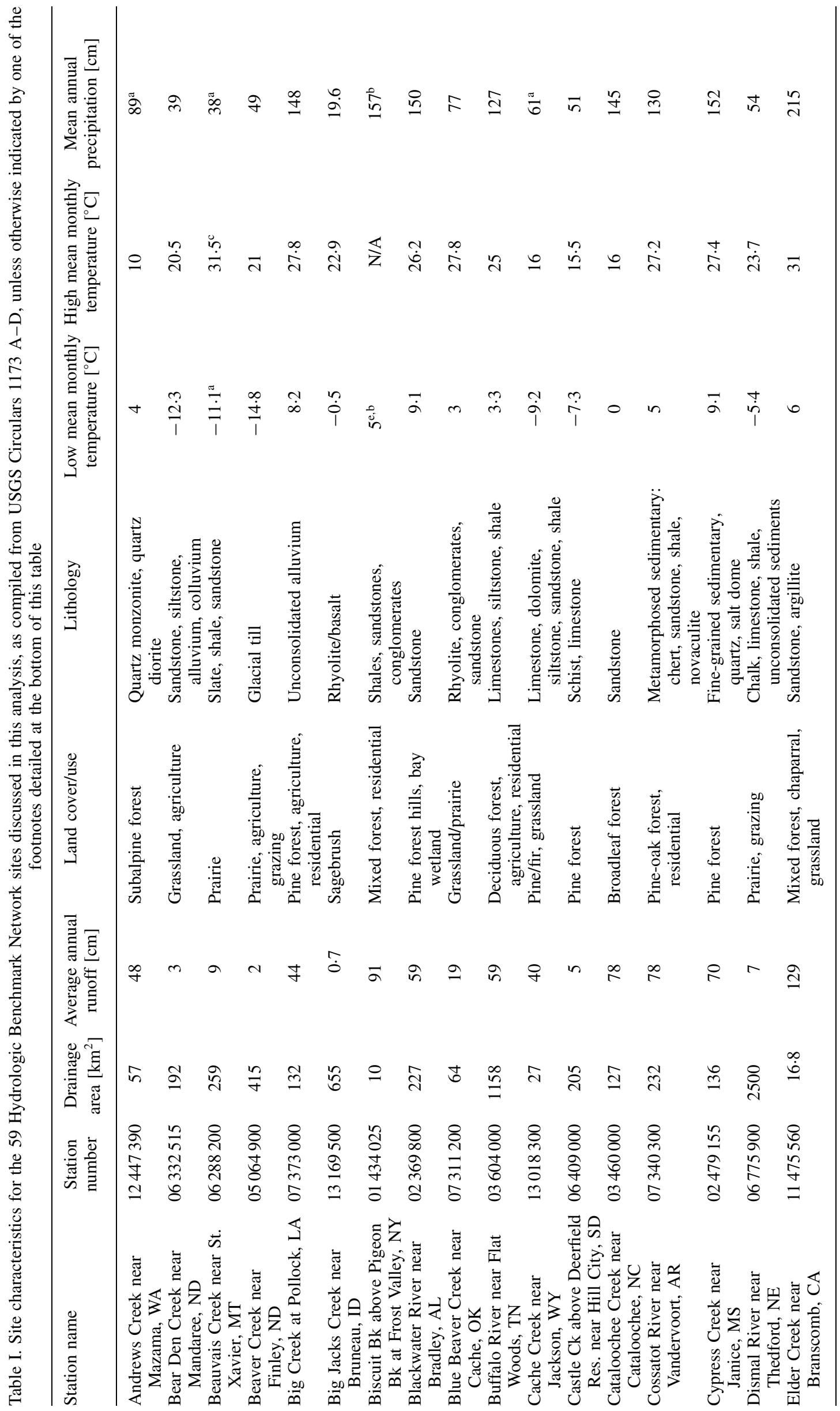




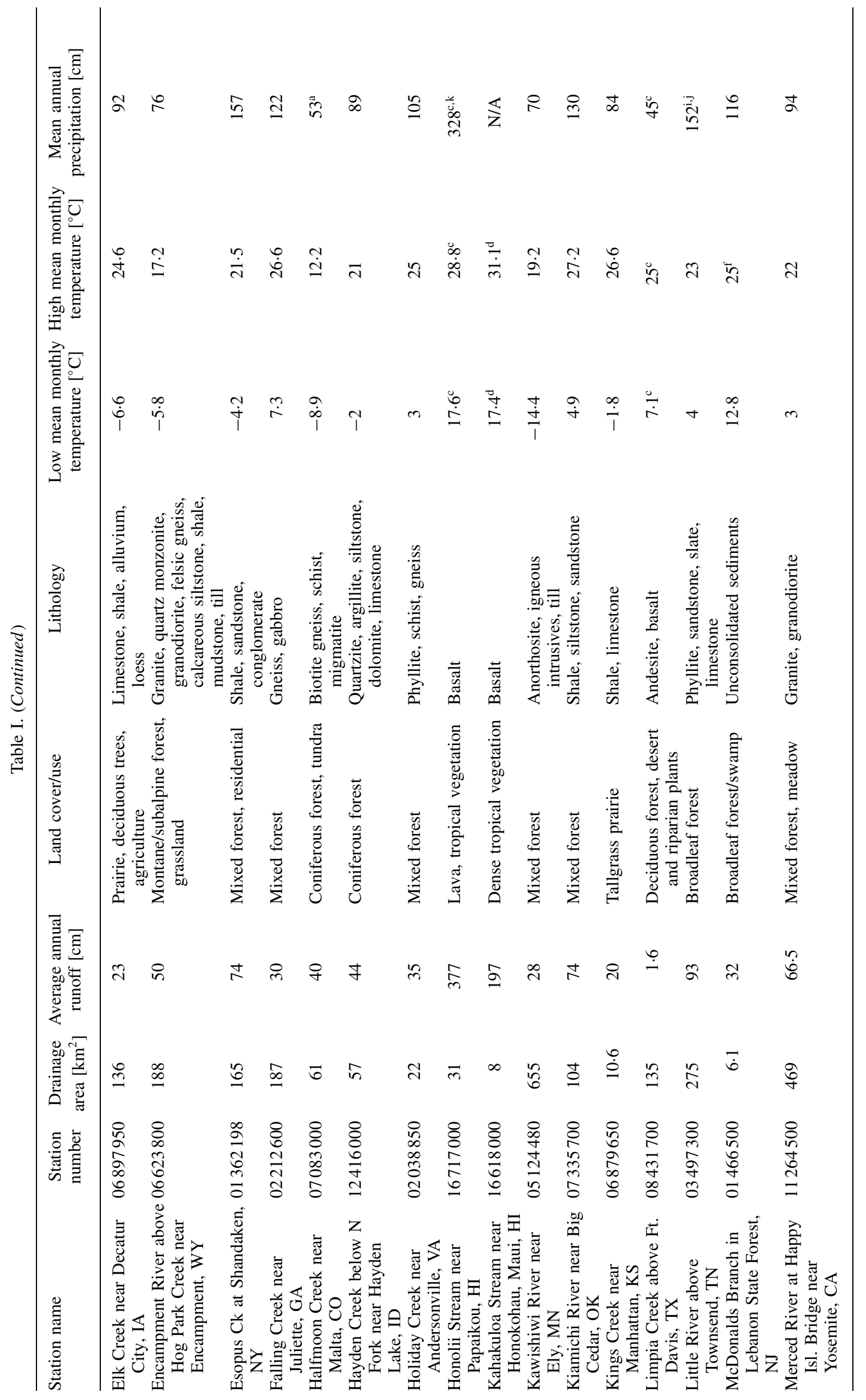




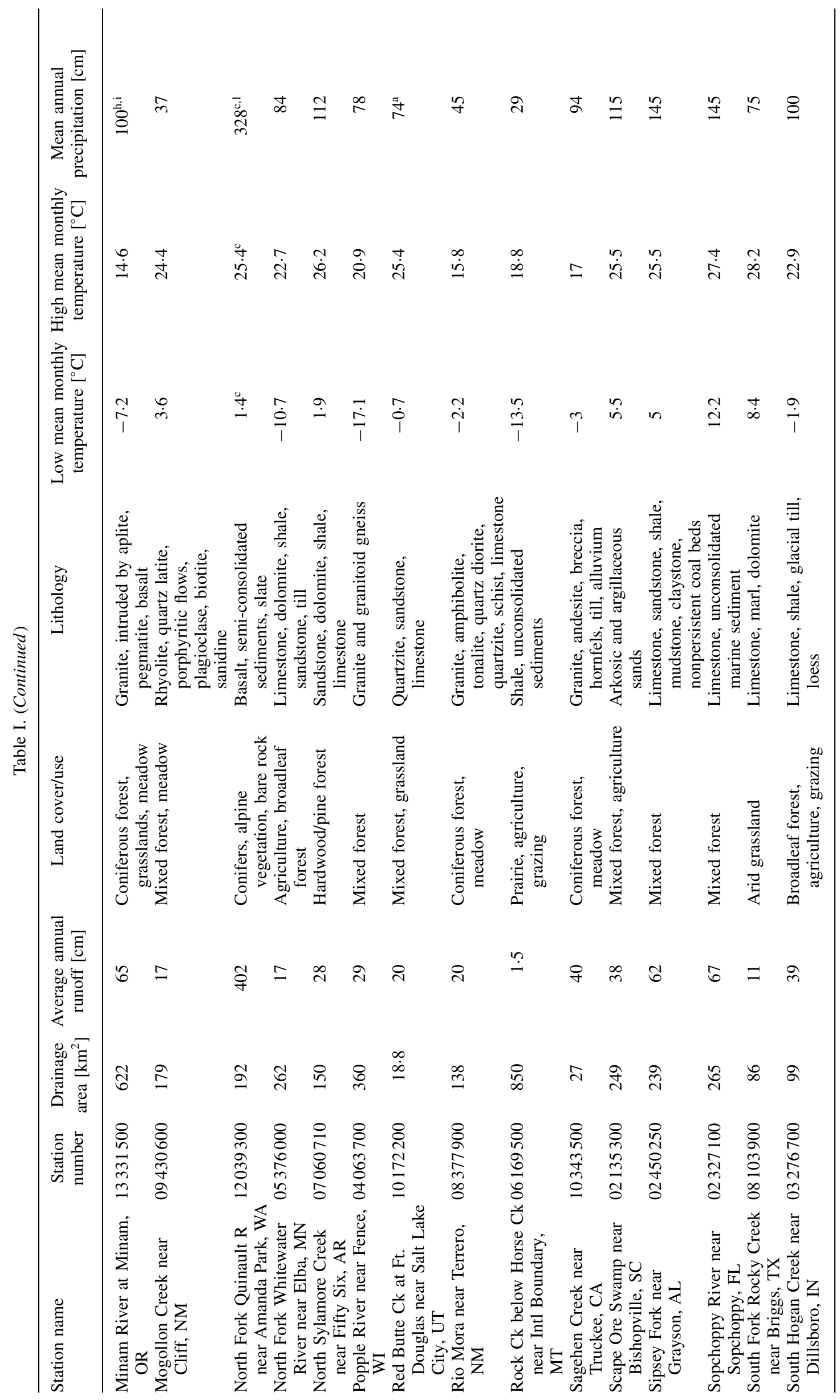




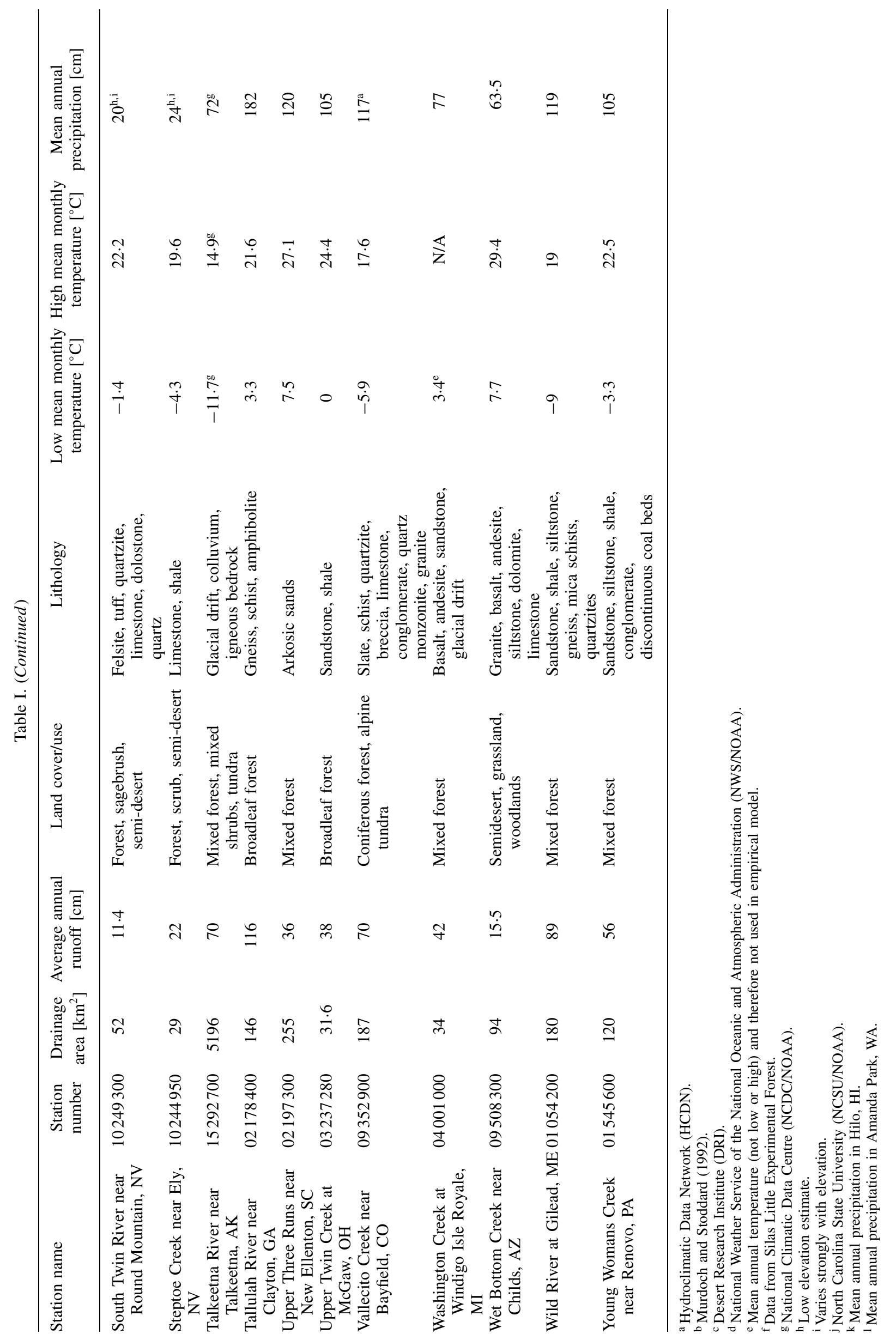



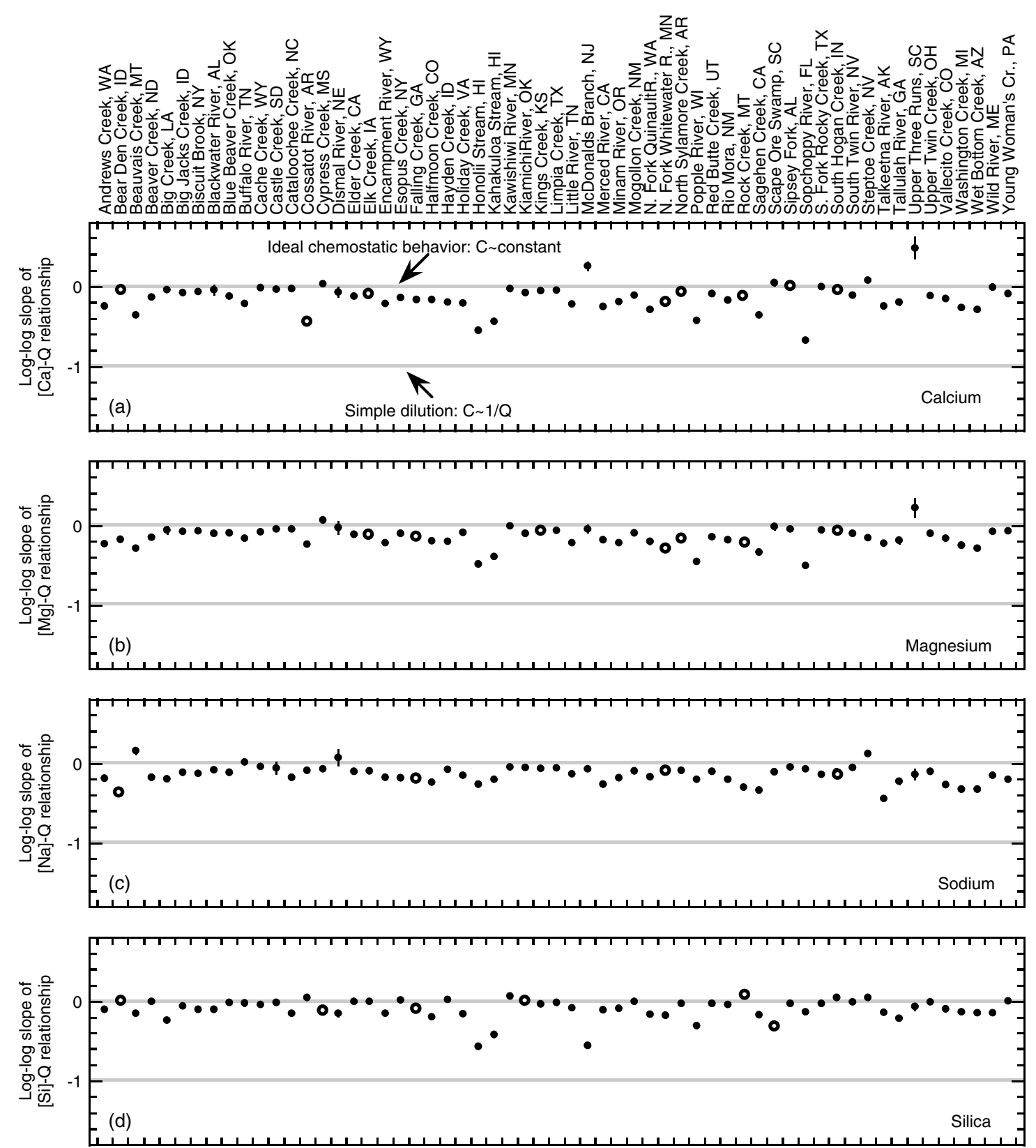

Figure 2. Log-log slopes of concentration-discharge relationships for 59 Hydrologic Benchmark Network streams arranged alphabetically by site name. Grey lines indicate slope values expected for ideal chemostatic behaviour (concentration held constant; log - log slope $=0$ ) and for simple dilution of a constant solute flux (concentration inversely proportional to discharge; $\log -\log$ slope $=-1$ ). With few exceptions, these catchments exhibit nearly ideal chemostatic behaviour for $\mathrm{Ca}, \mathrm{Mg}, \mathrm{Na}$ and $\mathrm{Si}$. Error bars indicate \pm 1 standard error, and are shown where they are larger than the plotting symbols. Open symbols indicate that the observed relationship appears to be non-linear in $\log -\log$ space.

chemostatically. We also verified that the samples collected are representative of the range of flows at each site. At all sites, samples are collected across a range of flows from the 5th to 97th flow percentiles (as calculated from the complete flow record reported in the USGS National Water Information System database, excluding dates on which flow is zero). Most sites include samples from the 1st to 99th percentiles of flow, and median HBN samples corresponded approximately to the 52nd flow percentile, suggesting that base flows are not oversampled.

A handful of sites have positive slopes for one or more solutes, which indicate that concentration increases with increasing flow (e.g. Upper Three Runs, SC for $\mathrm{Ca}$ and $\mathrm{Mg}$ and Steptoe Creek, NV for $\mathrm{Na}$ ). In past studies, increased concentrations of more biologically active ions such as $\mathrm{K}^{+}$and $\mathrm{NO}_{3}{ }^{-}$with increased flow have been attributed to leaching from organic soil horizons during higher flows (Walling and Webb, 1986). At the HBN sites, the observed increase in concentration of the major weathering products with discharge may be due to a weak correlation between discharge and concentration, or due to limited variability in the sampled discharge (e.g. discharge varies by only a factor of $\sim 4$ at Upper Three Runs). At Upper Three Runs, it also may be a result of analytical error or instrumentation changes in very dilute stream waters (Mast and Turk, 1999a, pp. 

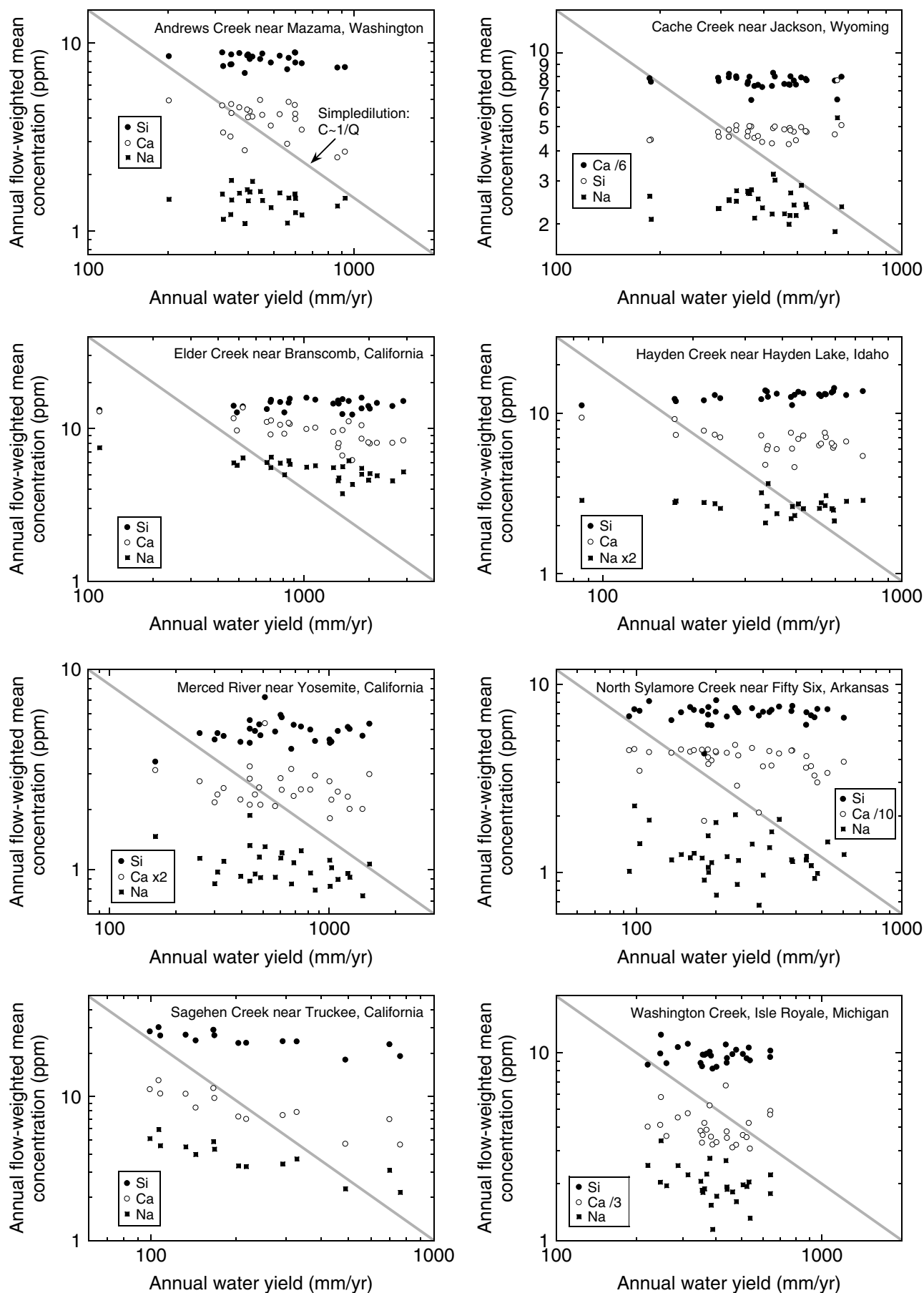

Figure 3. Annually averaged concentration-discharge relationships for $\mathrm{Si}, \mathrm{Ca}$ and $\mathrm{Na}$ at the same eight Hydrologic Benchmark Network streams shown in Figure 1. Each plot has consistent axes (same number of log units for both concentration and discharge), so concentrations determined by dilution of fixed weathering fluxes would have the same slope as the grey diagonal lines shown (log-log slope of -1$)$. Even on inter-annual time scales, concentration-discharge relationships do not generally follow the predictions of a simple dilution model, instead conforming more closely to chemostatic behaviour (log-log slope near zero).

108-110). However, most sites show little variability in concentration with discharge and we focus on these sites for the rest of this paper.

One might postulate that concentrations are relatively constant across wide ranges of discharge simply because the volume of water stored in a catchment is much larger than the amount discharged during an individual storm event. Therefore we also tested whether catchments behave chemostatically on inter-annual time scales. Annualized concentration-discharge relations for each of the HBN sites were plotted as mean annual flow-weighted concentrations against annual water yield. Water yield was calculated by summing all daily flows in the water year, as available from the daily USGS streamflow record, and dividing by catchment area. Mean flow-weighted concentrations were calculated as $\Sigma\left(Q_{i} C_{i}\right) / \Sigma Q_{i}$, where the subscript $i$ indicates each sample during the water year. We excluded years with fewer 

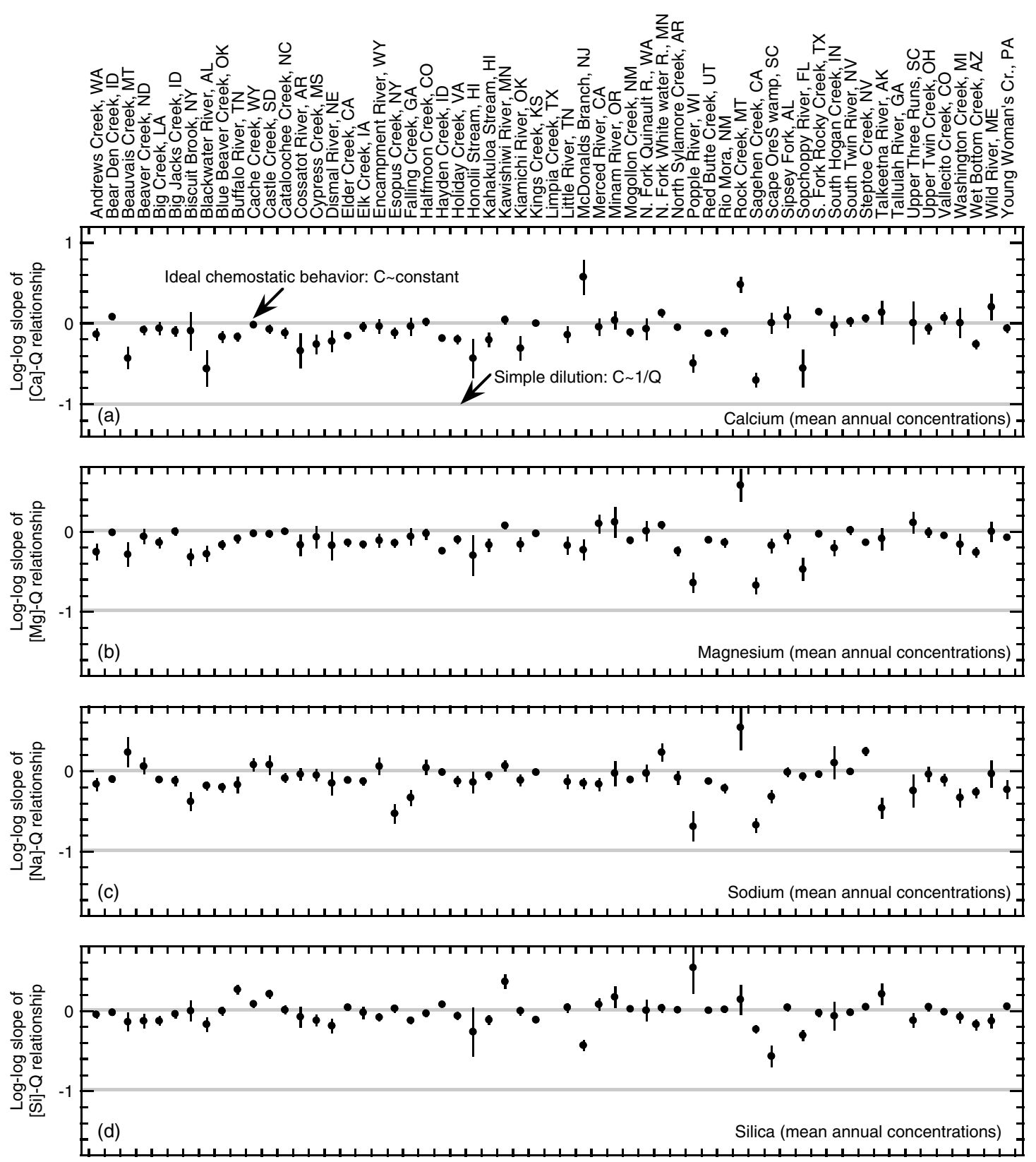

Figure 4. Log- $\log$ slopes of relationships between mean annual flow-weighted concentrations and mean annual discharge for 57 Hydrologic Benchmark Network streams (slopes are not shown for Limpia Creek, TX or Tallulah River, GA because too few years of data are available). Grey lines indicate slope values expected for ideal chemostatic behaviour (concentration held constant; $\log -\log$ slope $=0$ ) and for simple dilution of a constant solute flux (concentration inversely proportional to discharge; $\log -\log$ slope $=-1$ ). Even on inter-annual time scales, almost all of these catchments exhibit nearly ideal chemostatic behaviour for $\mathrm{Ca}, \mathrm{Mg}, \mathrm{Na}$ and $\mathrm{Si}$. Error bars indicate \pm 1 standard error calculated from a weighted least squares fit to the log annual flow-weighted concentration for each water year versus log annual water yield. The weighting function is equal to the inverse unbiased weighted variance of the log concentration. By unbiased, we mean that we account for a potential loss in the degrees of freedom introduced by variable flow by calculating the effective number of solute measurements per water year.

than four available concentration measurements from the inter-annual concentration-discharge analysis.

The plots of mean annual flow-weighted concentrations versus annual water yield exhibit similar patterns to those observed on an event basis (Figures 3 and 4). Mean annual concentrations vary much less than water yield does from year to year. The concentration-discharge plots for inter-annual time scales (Figure 3) are similar to those for individual samples (Figure 1); both exhibit power-law relationships between solute concentrations and water yields, with small negative $\log -\log$ slopes.
Across the HBN sites, these $\log -\log$ slopes are generally close to zero on both inter-annual time scales (Figure 4) and event time scales (Figure 2), although the error bars in Figure 4 are larger because the annualized concentration-discharge plots (e.g. Figure 3) have fewer points and a smaller range of discharge. The near-zero slopes imply that catchments exhibit near-chemostatic behaviour over both event and inter-annual timescales and across a wide range of hydrologically and geochemically diverse sites. Thus, an interesting first-order question is not why concentrations of weathering products 
vary, but why they vary so little as discharge changes so much.

\section{ASSESSMENT OF ALTERNATIVE MODELS}

Consistent near-zero $\log (C)-\log (Q)$ slopes imply that rates of solute production or mobilization must be nearly proportional to water fluxes on intra- and inter-annual timescales. Here we explore several simple quantitative explanations for the observed concentration-discharge patterns to verify if they hold across all the HBN sites, and to compare different possible models at each site. We evaluate these explanations on the basis of several key criteria. They should generate power-law relationships between concentration and discharge with small negative slopes and little hysteresis. Furthermore, they should have reasonable physical and chemical parameters and should make plausible assumptions about catchment behaviour. They should be as simple as possible and explain observations in a wide range of catchments. We examine several empirical, mixing and chemical models to gain insight into the linkages between chemical weathering and hydrologic processes that produce the observed concentration-discharge relationships. We quantitatively assess the models' performance at each site using the Akaike and Bayesian information criteria (AIC and BIC) for each set of comparable models.

\section{Empirical models}

We first evaluated whether the slope of the concentration-discharge relationship can be predicted as a simple empirical function of each catchment's characteristics, or as a multivariate model of several characteristics. For each site, we plotted average low and high temperature, annual average runoff, area, and Mean Annual Precipitation (MAP) against the event-based concentration-discharge slope for each solute, and calculated the correlation between each of these site characteristics and each solute's concentration-discharge slope (using the non-parametric Spearman correlation coefficient because the distributions of site characteristics are not normal). Based on the site descriptions from the USGS circulars (Mast and Turk, 1999a,b; Clark et al., 2000; Mast and Clow, 2000), we also coded each site according to the presence or absence of carbonates and volcanics in the underlying bedrock. We then used the Ftest (Zar, 1984) to determine whether the presence of either of these broad rock types significantly affected the concentration-discharge slope for any solute. For the multivariate models, we systematically added and removed characteristics from a series of multiple linear regression models and evaluated their performance.

The site characteristics that we tested generally do not satisfactorily explain the observed slopes of the concentration-discharge relationships (Table II). Steeper concentration-discharge slopes are associated with higher average annual runoff (although, surprisingly, not always with higher MAP); these correlations are statistically significant for some solutes but not others. Sites with volcanic bedrock have significantly $(p<0.05)$ steeper concentration-discharge slopes for $\mathrm{Ca}, \mathrm{Mg}$ and $\mathrm{Na}$ compared to sites where volcanics are absent. Similarly, $\log -\log$ slopes for $\mathrm{Na}$ are significantly $(p<$ 0.02 ) shallower at sites with carbonate bedrock, compared to sites without carbonates. Although some site characteristics show statistically significant effects on concentration-discharge slopes, their predictive power is weak because they explain only a small fraction of the variance; typical $r^{2}$ values are 0.1 or less. Multivariate models with combinations of these site characteristics could only explain $<20 \%$ of the variability in $\log (C)-\log (Q)$ slopes. We conclude that the observed variation in concentration-discharge slopes cannot be straightforwardly predicted by any of the site characteristics tested here. Other site characteristics, such as basin slope, soil permeability, or amount and type of soil and vegetation, might be useful explanatory variables, but they have not been quantified for most of the HBN basins. Basin slope and soil permeability, for example, might be important because they influence hydrological flow paths and the residence time of water in the basins.

\section{Mixing models}

We turn from empirical models based on site characteristics to simple models based on the mixing of waters with different compositions. Isotopic studies and other hydrometric and hydrochemical evidence have shown that in many catchments, typical residence times are much longer than the duration of individual storm events

Table II. Statistical tests of association between site characteristics and concentration-discharge slopes across the 59 HBN streams

\begin{tabular}{|c|c|c|c|c|}
\hline$F$ ratio & $\mathrm{Ca}$ & $\mathrm{Mg}$ & $\mathrm{Na}$ & $\mathrm{Si}$ \\
\hline Volcanics (present vs. absent) & $5 \cdot 32^{\mathrm{a}}$ & $6 \cdot 51^{\mathrm{a}}$ & $4 \cdot 59^{\mathrm{a}}$ & $3 \cdot 77$ \\
\hline Carbonates (present vs. absent) & 0.07 & 0.02 & $12 \cdot 47^{\mathrm{b}}$ & $2 \cdot 54$ \\
\hline $\begin{array}{l}\text { Spearman correlation } \\
\text { coefficient, } \mathbf{r}_{\mathrm{s}}\end{array}$ & $\mathrm{Ca}$ & $\mathrm{Mg}$ & $\mathrm{Na}$ & $\mathrm{Si}$ \\
\hline
\end{tabular}

\begin{tabular}{|c|c|c|c|c|}
\hline Aver & $-0.27^{a}$ & -0.19 & $-0 \cdot 21$ & $-0.28^{a}$ \\
\hline low temperature & -0.02 & $0 \cdot 10$ & 0.06 & $-0 \cdot 30^{\mathrm{a}}$ \\
\hline $\begin{array}{l}\text { Average high temperature } \\
\text { (deg C) }\end{array}$ & 0.06 & 0.06 & $0 \cdot 25$ & $-0 \cdot 16$ \\
\hline $\begin{array}{l}\text { MAP, Mean annual } \\
\text { precipitation }(\mathrm{cm})\end{array}$ & 0.03 & 0.05 & -0.08 & $-0 \cdot 2$ \\
\hline Area $\left(\mathrm{km}^{2}\right)$ & $-0 \cdot 11$ & -0.08 & 0.00 & 0.04 \\
\hline
\end{tabular}

Superscripts $\mathrm{a}$ and $\mathrm{b}$ indicate statistical significance at the $p<0.05$ and $p<0.02$ levels, respectively. Several of the tested relationships are statistically significant but their explanatory power is low. Sites with volcanic bedrock have steeper concentration-discharge slopes for $\mathrm{Ca}$, $\mathrm{Mg}$ and $\mathrm{Na}$ than sites without volcanics, and slopes for $\mathrm{Na}$ are shallower at sites with carbonate bedrock compared to sites without carbonates. Nonparametric (Wilcoxon) tests agree with the parametric (F-test) results. Average annual runoff is significantly correlated with $\mathrm{Ca}$ and $\mathrm{Si}$ slopes, and average low temperature and MAP with Si slopes, according to the robust Spearman rank correlation coefficient. 
(e.g. Buttle, 1994). One can imagine that residence times may be long enough for weathering reactions to approach equilibrium, and that this explains the chemostatic behaviour observed across the HBN sites. Sufficient storage capacity for the 'old' water must exist for this option to be physically plausible, and we explore storage requirements for different models below. In general, we find that mixing models that assume a constant rate of solute supply generally cannot reproduce the observations well.

First, we present a simple 'bucket' mixing model that treats the catchment as a single well-mixed reservoir whose volume $\left(V,\left[\mathrm{~m}^{3}\right]\right)$ remains constant as discharge $\left(Q_{w},\left[\mathrm{~m}^{3} / \mathrm{s}\right]\right)$ varies. The model likewise assumes that the solute flux $\left(Q_{s},\left[\mathrm{ppm}-\mathrm{m}^{3} / \mathrm{s}\right]\right)$ produced by mineral weathering is constant through time. It further assumes that concentrations in precipitation are very dilute compared to streamflow (as is typically the case for the major weathering products), so that precipitation solute fluxes can be ignored in the mass balance. Under these conditions, the solute concentration $(C,[\mathrm{ppm}])$ in the well-mixed reservoir, and thus in its outflow, will evolve according to the familiar mass-balance equation:

$$
\frac{\mathrm{d} C}{\mathrm{~d} t}=\frac{\left(Q_{s}-Q_{w} C\right)}{V}
$$

where $Q_{w}$ is the average daily water flux through the reservoir, for which we use the USGS historical daily flow record. We fix the solute flux $\left(Q_{s}\right)$ equal to the product of the average water flux and the flow-weighted average concentration, so that the average modeled solute flux will equal the observed long-term average. The reservoir volume $(V)$ is the only free parameter, which is adjusted to reproduce the observed range of variation in outflow concentrations.

Constraining the concentrations modeled using Equation (1) within the bounds of observed variability in the HBN data set requires a storage volume that is well-mixed to depths of several meters throughout the

Table III. Subsurface storage depths required for a simple 'bucket' model assuming a constant $5 \%, 10 \%$ and $30 \%$ porosity for the model described in Equation (1) of the text

\begin{tabular}{lccc}
\hline Site & \multicolumn{3}{c}{ Storage Depth (m) } \\
\cline { 2 - 4 } & 5\% porosity & 10\% porosity & 30\% porosity \\
\hline Andrews & $10 \cdot 8$ & 5.4 & 1.8 \\
Cache & 10.1 & 5.0 & 1.7 \\
Elder & 83.7 & 41.9 & 14.0 \\
Hayden & 6.0 & 3.0 & 1.0 \\
Merced & 9.8 & 4.9 & 1.6 \\
N Sylamore & 6.5 & 3.3 & 1.1 \\
Sagehen & 21.7 & 10.9 & 3.6 \\
Washington & 9.2 & 4.6 & 1.5 \\
\hline
\end{tabular}

The porosity is a single average value for all soil and underlying bedrock to the specified depth. The specified storage depth indicates the volume required to maintain the observed variability in concentrations at a given site (reported value is the median storage for all four solutes based on the observed ratio of maximum to minimum concentrations at each site, the median of which is $\sim 4$ across all sites and solutes). catchment (Table III) for a porosity of $10 \%$ (averaged across both soil and underlying rock). Higher porosities require a smaller storage volume whereas lower porosities require a larger storage volume. Even with sufficiently large storage volumes, however, modeled concentration-discharge relationships do not match the observations well; the model results exhibit large hysteresis loops that are not present in the observations (Figure 5a). These loops result from the assumption that the catchment behaves as a simple well-mixed bucket: the integro-differential relationship in Equation (1) implies a 90-degree phase lag between changes in discharge and changes in concentration, rather than the simultaneous variations in concentration and discharge that are usually observed. Hysteresis loops are frequently observed in concentration-discharge relationships, but the extent of looping modeled in Figure 5a is much greater than is typically observed (e.g. Evans and Davies, 1998). To match the observed concentration-discharge relationships, this model would have to be modified to allow solutes to be: (1) produced at a variable rate or (2) mobilized from different sources at variable rates.

Another well-known model that we consider is the Hubbard Brook 'working model' (Johnson et al., 1969) which assumes that discharge is proportional to storage volume $\left(V,\left[\mathrm{~m}^{3}\right]\right)$, and that solute concentrations $(C,[\mathrm{ppm}])$ associated with each storage volume are fixed. Storage volume is defined as the subsurface pore space available above an 'impermeable' layer. $C$ is then inversely related to $Q$ according to:

$$
C=\left[\frac{d}{(1+b Q)}\right]+a
$$

where $a=$ concentration of solute in the low-concentration end-member $[\mathrm{ppm}], b=$ mean residence time $/ V_{Q=0}$ (flows at the catchment outlet are assumed to cease at some non-zero storage volume, $\left.V_{Q=0}\right)\left(\mathrm{s} / \mathrm{m}^{3}\right)$, and $d=$ concentration difference between high and low concentration waters [ppm]. Any non-zero flow is directly proportional to water in storage above the minimum volume. One can immediately see that this model does not represent a power-law relationship between $C$ and $Q$, but instead that the relationship is a hyperbolic function. However, because it has an additional free parameter, Equation (2) can also fit the data well (Figure 5b). A non-linear fitting algorithm which minimizes the sum of squared error between the model results and observed data is used to select best-fit values of $a, b$, and $d$. The parameter $b$ depends only on the mean residence time of water in the catchment and the minimum volume required for flow in the stream. Importantly, $b$ does not depend on the solute of interest; therefore, it should have the same value for all the solutes at an individual site. This consistency in $b$ can be ensured by simultaneously fitting all solutes in a given catchment. Johnson et al. (1969) suggest that $a$ should be thought of as the 'rainwater' concentration of each solute. However, the best-fit $a$ values exceed measured volume-weighted precipitation concentrations for $\mathrm{Ca}, \mathrm{Mg}$ and $\mathrm{Na}$ [as reported in Mast and Turk 

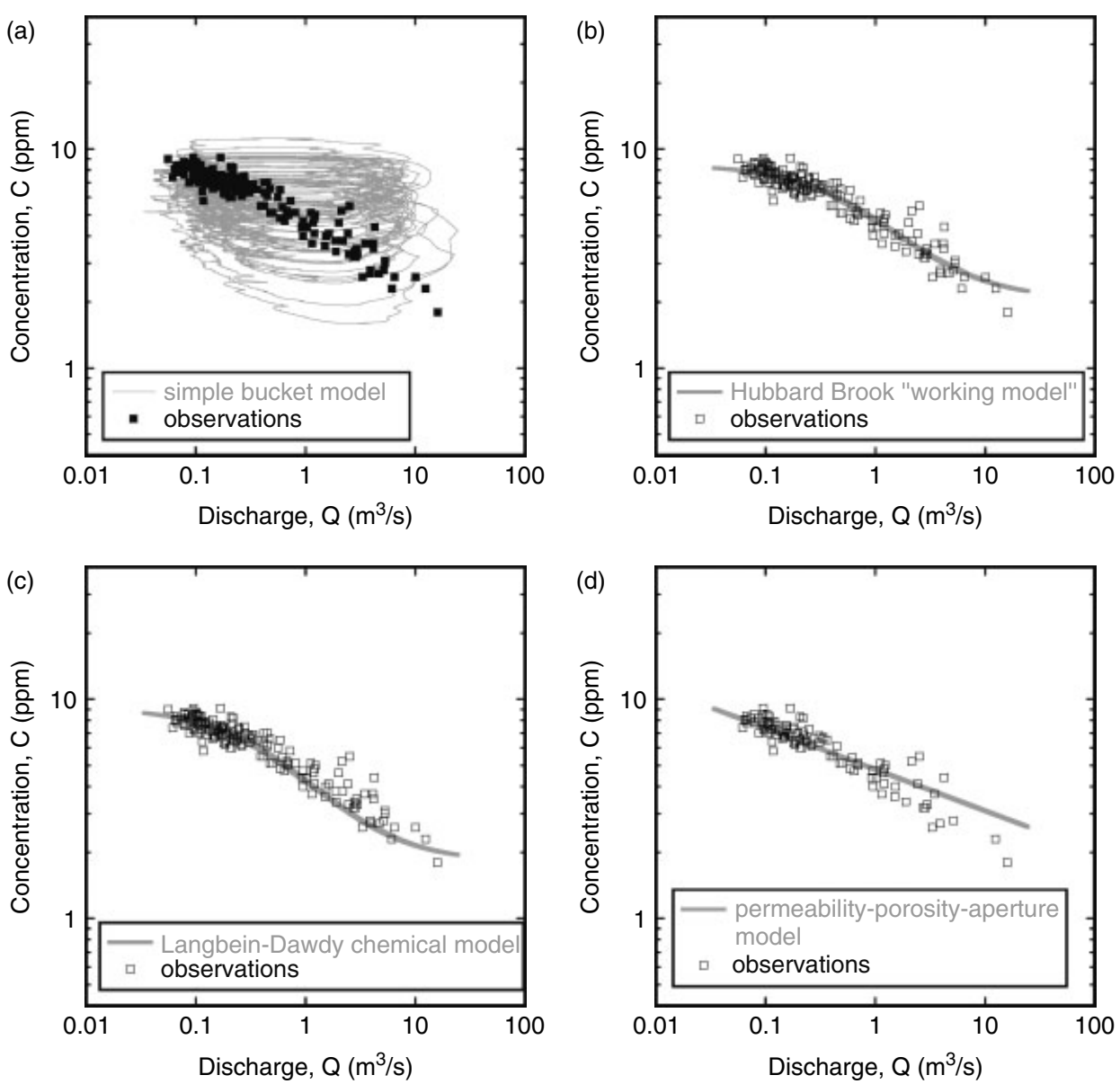

Figure 5. Concentration (C)-discharge (Q) relationships for several models plotted with the observed values for Ca at Andrews Creek in Mazama, WA. (a) A well-mixed reservoir model (Equation (1)) with a very large storage volume can reproduce the observed range in concentration variability, but only with excessively large hysteresis loops that are not observed in the real data. (b) Inverse relationship between $C$ and $Q$ as specified by the Hubbard Brook 'working model' (Johnson et al., 1969) generally matches the form for each solute, but best-fit $a$ parameters (Eq. 2) exceed observed rainfall concentrations (Table IV). (c) Langbein and Dawdy's (1964) chemical mixing model can fit the data well but allows no storage of water or mixing of waters of different ages in the catchment. (d) The permeability-porosity-aperture model (see text) can also fit the data reasonably well, although its assumptions still need to be tested in the field. The slight overestimate of concentration at high discharges is due to the simultaneous fitting to all four solutes with one hydrologic parameter, $b_{0}$, which is the best-fit slope to all four solutes' concentration-discharge data. See text for more detailed discussion.

(1999a,b); Clark et al. (2000); Mast and Clow (2000)] by up to two orders of magnitude (Table IV). Concentrations of $\mathrm{Si}$ in precipitation are not generally reported, but the best-fit $a$ for $\mathrm{Si}$ is in the range of $\sim 10 \mathrm{ppm}$. Instead of representing 'rainfall' concentrations, the high best-fit $a$ values could perhaps be thought of as 'soil water' concentrations. In any case, the fact that the best-fit values of $a$ are much higher than rainfall concentrations implies

Table IV. Best-fit parameter $a$ in the Hubbard Brook 'working model' and observed precipitation concentrations for the major base cations at eight representative sites

\begin{tabular}{|c|c|c|c|c|c|c|}
\hline All (ppm) & Best-fit $a_{\mathrm{Ca}}$ & $\begin{array}{l}\text { Observed } \mathrm{Ca} \text { in } \\
\text { precipitation }\end{array}$ & Best-fit $a_{\mathrm{Mg}}$ & $\begin{array}{l}\text { Observed } \mathrm{Mg} \text { in } \\
\text { precipitation }\end{array}$ & Best-fit $a_{\mathrm{Na}}$ & $\begin{array}{c}\text { Observed } \mathrm{Na} \text { in } \\
\text { precipitation }\end{array}$ \\
\hline Andrews & $2 \cdot 04$ & 0.03 & $0 \cdot 31$ & 0.02 & 0.97 & 0.07 \\
\hline Cache & $44 \cdot 1$ & $0 \cdot 19$ & $12 \cdot 3$ & 0.02 & $2 \cdot 20$ & $0 \cdot 04$ \\
\hline Elder & $7 \cdot 21$ & $0 \cdot 04$ & $2 \cdot 34$ & 0.04 & $4 \cdot 32$ & $0 \cdot 18$ \\
\hline Hayden & 4.23 & $0 \cdot 11$ & $1 \cdot 31$ & 0.04 & $1 \cdot 13$ & 0.01 \\
\hline Merced & 0.72 & 0.05 & $0 \cdot 10$ & 0.01 & 0.56 & 0.04 \\
\hline N Sylamore & $28 \cdot 6$ & $0 \cdot 14$ & 1.89 & 0.02 & 0.82 & 0.05 \\
\hline Sagehen & $3 \cdot 56$ & 0.05 & $1 \cdot 36$ & 0.01 & 1.75 & 0.04 \\
\hline Washington & 7.99 & $0 \cdot 16$ & $2 \cdot 44$ & 0.03 & $1 \cdot 14$ & 0.02 \\
\hline
\end{tabular}

Observed Si concentrations in precipitation were not available. The best-fit concentrations, $a$, are observed to be one to two orders of magnitude higher than the observed concentrations. This suggests that the model is unable to represent some mixing or reaction processes occurring in the catchment. In all cases, all three parameters in Equation (2) were fit simultaneously for all four solutes; $a$ and $d$ were constrained to be $\geq 0$, and $b$, which depends only on hydrology and is independent of the solute, was forced to be a single value for all four solutes at each site. 
that important solute sources within the catchment are not captured by the model.

\section{Chemical models}

On the other end of the modeling spectrum, one could assume that waters react so rapidly with soil and rock that one can ignore mixing of waters of different ages altogether. If changes in chemical reactions were solely responsible for the concentration-discharge patterns we see, what would this imply? The simplest way to maintain chemical concentrations as discharge increases is through a combination of increasing reactive surface area and increasing reaction rates.

A simple approach was proposed by Langbein and Dawdy (1964) who assumed that dissolution rate varies between zero and the maximum dissolution rate, $D$, depending upon distance from equilibrium. They also assumed that the dissolved load is removed as quickly as it is formed, which is equivalent to assuming that mixing of water of different ages is negligible. To generalize their model from 1 st order to nth-order reactions, one can let the forward reaction be equal to $D A[\mathrm{~mol} / \mathrm{s}]$ where $A$ $\left[\mathrm{m}^{2}\right]$ is the reactive surface area, and let the back reaction be equal to $D A\left(C / C_{s}\right)^{n}$ where $n$ [dimensionless] is the order of the reaction, $C\left[\mathrm{~mol} / \mathrm{m}^{3}\right]$ is the concentration and $C_{s}\left[\mathrm{~mol} / \mathrm{m}^{3}\right]$ is the concentration at saturation. The load, $L[\mathrm{~mol} / \mathrm{s}]$, would then be equal to the balance of the forward and backward reactions:

$$
L=D A\left[1-\left(C / C_{S}\right)^{n}\right]
$$

Assuming that the dissolved load is removed as quickly as it is formed, one can also write:

$$
L=Q\left(C-C_{o}\right)
$$

where $C_{o}\left[\mathrm{~mol} / \mathrm{m}^{3}\right]$ is the initial (i.e. rainfall) concentration, $C\left[\mathrm{~mol} / \mathrm{m}^{3}\right]$ is the final concentration and $Q\left[\mathrm{~m}^{3} / \mathrm{s}\right]$ is the discharge. For first- and second-order reactions ( $n=1$ or 2, respectively), Equations (3) and (4) can be solved for $C$ as a function of $Q$ :

$$
(\text { for } n=1) \quad C=\frac{D A+Q C_{o}}{Q+D A / C_{s}}
$$

or

$$
(\text { for } n=2) \quad C=\frac{Q-\sqrt{Q^{2}+\frac{4 D A}{S^{2}}\left(D A+Q C_{o}\right)}}{-2 D A / C_{s}{ }^{2}}
$$

where the negative root for $n=2$ gives the concentration that has physical meaning. Using these equations and the observed concentration-discharge relationships, one can determine the values of $D A, C_{s}$ and $C_{o}$ that are required to fit the data. With three adjustable parameters, the model approximately reproduces the observed concentration-discharge relationship with either $n=1$ or $n=2$, although the $\log -\log$ relationship is curved rather than linear (Figure 5c). The order of the reaction does not strongly affect the overall quality of fit, but the dissolution rate times area $(D A)$ parameter for the best-fit 2 nd order scenario differs from the 1 st order case. One cannot distinguish among models of different reaction order given only concentration-discharge data; additional a priori information about the order of the reaction or the dissolution rate and reaction area is needed to distinguish among the models. The best-fit saturated concentration is lower than the observed maximum concentration and the best-fit initial concentration is higher than the observed minimum concentration; the best-fit concentrations vary little as reaction order changes. In either case, the bestfit initial concentration is usually much higher than is realistic for rainfall. Rather than representing rainfall, the best-fit $\mathrm{C}_{\mathrm{o}}$ probably reflects solutes acquired during infiltration through the soil column before reaching the groundwater system. Although multiple versions of the Langbein and Dawdy model fit the data reasonably well, the key assumption that there is no storage of water between storms and therefore negligible mixing of water of different ages is generally not valid (e.g. Buttle, 1994).

\section{Permeability-porosity-aperture model}

Here we suggest another model that is the only general model that we know of that produces a power-law relationship between concentration and discharge, assumes a variable solute flux that is proportional to the reactive surface area, and allows for mixing of waters of different ages. This final point distinguishes this model from the Langbein-Dawdy model.

The full derivation is shown in the appendix. The key assumptions are that permeability, porosity and average pore aperture or width, all decrease exponentially with depth; that Darcy's Law describes flow through the catchment; that the effective precipitation rate is approximately spatially uniform across a hillslope; that flows originating near the divide and stream are minimal; and that solute flux is proportional to reactive surface area such that secondary and back-reactions do not control solute fluxes.

One can show that under these assumptions, the volume-weighted mean concentration $\left(\bar{C},\left[\mathrm{~mol} / \mathrm{m}^{3}\right]\right)$ draining a one-dimensional hillslope will be a power function of the water flux $\left(Q_{w}\right)$,

$$
\bar{C}=a_{o} Q_{w}^{b_{0}}, b_{0}=\left(\lambda_{k} / \lambda_{\phi}-\lambda_{k} / \lambda_{p}-1\right)
$$

where the constant $a_{o}$ is a function of solute and catchment characteristics, and the power-law exponent $b_{0}$ (dimensionless) depends on the rate at which permeability, porosity and pore aperture decrease exponentially with depth in the subsurface (represented by the e-folding length scales $\lambda_{k}, \lambda_{\phi}$ and $\lambda_{p}$, all in [m]). Because $\lambda_{k}$, $\lambda_{\phi}$ and $\lambda_{p}$ are geometric properties of the subsurface and are not specific to individual solutes, equation (6) implies that $b_{o}$ should be the same for all weatheringderived solutes at an individual site (see, for one example, 
Figure 5d showing $\mathrm{Ca}$ at Andrews Creek). We fitted a single value of $b_{o}$ for each site, and a value of $a_{o}$ for each site and solute, using a non-linear fitting algorithm that minimizes the error between the modeled and observed concentrations for all solutes simultaneously.

Because we fit some models to all the solutes simultaneously whereas we fit other models to each solute independently, comparing the models is not a straightforward exercise. Using the AIC or BIC, or by looking at the example in Figure 5, it is clear that the Langbein-Dawdy model (5b) outperforms the simple mixing model (5a). The permeability-porosity-aperture model (5d) outperforms the Hubbard Brook Experimental Forest 'working model' (5c) according to the AIC and BIC at each of the eight featured sites. Comparisons between the Langbein-Dawdy and permeability-porosityaperture model cannot be made using the AIC or BIC because the models are based on different sets of data (fitting each solute independently vs. all solutes simultaneously). Regardless of model performance, a key test of each of these models is whether the best-fit parameters make physical and chemical sense in the real-world catchments in which they are applied.

Contrary to the prediction of the permeability-porosityaperture model, that the log-log slope $b_{0}$ of the concentration-discharge relationship should be the same for different weathering products at an individual catchment, the $\log (C)-\log (Q)$ slopes for different solutes at the same site often differ by more than their uncertainties. This result could be explained by different depth profiles in the abundances of different minerals (and thus their reactive surface areas per unit pore surface). Mathematically this could be represented as $\lambda_{p}$ taking on different values for different solutes, although this would imply that $p$ would reflect not only pore aperture but also the relative abundances of different minerals. However, because $b_{0}$ is usually close to zero for different solutes, it is possible that the variation in $\lambda_{p}$ may be small. Another parameter, $b_{1}$, has been shown to relate storage and discharge in catchments, and is expressed as a function of the parameters $\lambda_{k}$ and $\lambda_{\phi}$ (Kirchner, 2009; and see Appendix, Equation A12 and A13). The two log-log slopes $b_{0}$ and $b_{1}$ are not sufficient to uniquely constrain the three parameters $\lambda_{k}, \lambda_{\phi}$ and $\lambda_{p}$, so the individual $e$-folding depths (as well as values of the reactivity parameter $k_{R}$ for each solute, see Appendix) could only be determined by direct measurement. Any such attempt at direct measurement, however, would be complicated by the spatial heterogeneity in subsurface properties, as well as the large differences between field and laboratory weathering rates (Schnoor, 1990; Brantley, 1992; White et al., 1996).

The mechanism proposed here is in some ways analogous to that proposed by Clow and Drever (1996) to explain the relatively constant concentrations of weathering products in runoff from an alpine soil under widely varying rainfall. Clow and Drever (1996) argued that Si concentrations in their study catchment may be controlled by flushing and diffusion from micropores and seasonal precipitation/dissolution of metastable amorphous aluminosilicates. They argued that because both flushing and reaction rates increase with increasing discharge, this combination of mechanisms would allow concentrations to remain relatively constant with fluctuating discharge. But whereas Clow and Drever (1996) argued that the rate of $\mathrm{Si}$ dissolution from the mineral phase should be controlled by Si concentrations in solution (and thus by the fluid flushing rate), here we assume that silicate weathering reactions are always far from equilibrium and thus are unaffected by changes in solute concentrations. Instead, in the permeability-porosity-aperture model outlined in Equation 6 and in the appendix, reaction rates increase at higher discharges because the wetted mineral surface area increases. Others have also argued that because $\mathrm{Si}$ is retained by secondary minerals to varying degrees, its concentration may be controlled in large measure by equilibration with respect to the secondary minerals that form (Drever and Clow, 1995; Godderis et al. 2006). Secondary mineral formation should preferentially affect $\mathrm{Si}$ and may explain why the power-law concentration-discharge slopes for Si are generally shallower than for the other major weathering products. These examples illustrate that different mechanisms can potentially generate similar observed concentration-discharge relationships, so it is important to verify the site-specific plausibility of any proposed mechanism.

\section{FURTHER POSSIBILITIES}

Many catchment-based chemical weathering models, such as Birkenes, ETD (Enhanced Trickle-Down), ILWAS (Integrated Lake Watershed Acidification Study), PROFILE/SAFE (Soil Acidification in Forested Ecosystems), MAGIC (Model of Acidification of Groundwater in Catchments), or WITCH [see review in Nordstrom (2004), pp. 60-62; Godderis et al., (2006)], and other mineral weathering models such as PHREEQC (Parkhurst and Appelo, 1999), allow the simulation of weathering processes. We do not use these models in this study because most of our sites have insufficient information to apply them. Instead we explore in this paper whether a simple general modeling approach is possible based primarily on the observed concentration-discharge relationship. We show that several simple models can fit the observations well, but often they require unrealistic or internally inconsistent parameter values. Because data limitations have precluded us from testing more complex models, we cannot say whether their added complexity, and additional data requirements, would be helpful in understanding catchments' concentration-discharge behaviour. Future studies could also examine the geomorphic features, soil or regolith depth, presence of organic matter, or perennial/ephemeral status of the catchments, which may control weathering rates or fluxes in some catchments (e.g. Drever, 1994; Oliva et al., 1999; Johnson et al., 2001). These characteristics have not been considered in this study. 
The relative constancy of concentrations across wide ranges of discharge requires solute production or solute mobilization at rates nearly proportional to the water flux. Depending on the relationship between reaction times and water transit times, one can infer the relative importance of production and mobilization. Based on field experiments, reaction rates have sometimes been inferred to be fast enough that the time to equilibrium is much shorter than average water transit times, such that waters are effectively always near equilibrium (e.g. Anderson and Dietrich, 2001). Buttle (1994) and many others have documented that most water reaching a stream during a storm event is so-called 'old' (i.e. pre-storm) water. Mean transit times in many catchments are on the order of $\sim 1$ year (McGuire and McDonnell, 2006, Table I), so this 'old' water may be near equilibrium with respect to certain minerals, with the consequence that solute fluxes mobilized by this 'old' water must be nearly proportional to water flux. However, studies of silicate weathering have typically found that reaction rates are slow (even relative to mean transit times of a year) and have assumed that catchments are kinetically-limited systems (see discussion in Brantley, 2004). Because the chemical weathering kinetics of silicates and carbonates differ (e.g. Brantley, 2004), one might expect different $\log (C)-\log (Q)$ behaviour or explanatory models for catchments dominated by the distinct lithologies. However, for most of the solutes considered, the concentration-discharge slopes are not significantly different between the different lithologic settings. This suggests that differences in lithology and in reaction kinetics between carbonates and silicates do not significantly alter the relationship between concentration and discharge across the study sites. Time to equilibrium in the laboratory for mineral-water equilibrium reactions has been reported as a week to a year or longer (e.g. Bricker, 1968; Langmuir, 1997, Table 2.1) and field rates are even slower (Schnoor, 1990; Brantley, 1992; White et al., 1996). This suggests that mineral weathering reactions would be unlikely to stay close to equilibrium, particularly during high flows. Determining the average time to equilibrium in the field is challenging: flow paths are heterogeneous and reactions and reactive surface areas are difficult to define. Nonetheless, as the preceding discussion illustrates, there would be much to be gained from determining how close weathering reactions are to equilibrium in the field.

\section{IMPLICATIONS}

Because concentrations are relatively constant with discharge across these diverse study catchments (Figures 1 and 2), solute fluxes (defined as concentration times discharge) from these catchments change nearly proportionally to discharge, both on an event basis and on an inter-annual basis (e.g. Figure 6). Although our observations are drawn from US catchments, these results are likely to be broadly generalizable because the HBN catchments include a broad range of climatic and lithologic environments (Table I). A similar relationship between concentration and discharge is also seen in granitic boreal catchments in permafrost regions of Russia (Zakharova et al., 2005), suggesting these observations and implications may be globally applicable. Climate change may substantially alter stream flows (especially if precipitation and evapotranspiration change in opposite directions). Such hydrologic changes will have little effect on concentrations but will alter fluxes almost proportionally.

Alkalinity flux to the ocean can be estimated as the sum of the $\mathrm{Ca}$ and $\mathrm{Mg}$ concentrations (McSween et al., 2003, p. 147), or the hardness of the water. Raymond and Cole (2003) used this approach to estimate alkalinity for the Mississippi River for years before 1973 using hardness. They showed that overlapping alkalinity and carbonate hardness (=total hardness - noncarbonate hardness) measurements are accurate to $99.8 \pm 0.8 \%$. Thus, we can estimate alkalinity fluxes based on the relationships between $\mathrm{Ca}, \mathrm{Mg}$ and discharge presented in Figures 2 and 4. Raymond and Cole (2003) found that discharge and alkalinity flux in the Mississippi River increased by approximately $44 \%$ and $70 \%$, respectively, over 48 years (1953-2001), attributed partially to changes in climate as well as changes in cropping patterns and additions from groundwater pumping. Based on the patterns in Figure 6 (and similar results for other solutes), one would expect solute flux from most watersheds across North America to vary nearly proportionally to water fluxes. Unlike the Mississippi River, most of the streams and rivers in the HBN are minimally affected by land use change or large amounts of groundwater pumping. Nonetheless, the nearly chemostatic behaviour demonstrated across so many diverse sites implies that alkalinity flux is largely determined by stream discharge. Streamflows at high latitudes are expected to increase by 10 to $40 \%$ over the next century, according to the latest report of the Intergovernmental Panel on Climate Change (IPCC, Core Writing Team, 2007). For a $10 \%$ increase in average annual flows, we would expect an approximately proportional $10 \%$ increase in alkalinity fluxes to the oceans. Carbonic acid weathering is one of the main mechanisms generating alkalinity; thus, an increase in alkalinity fluxes implies a concomitant increase in $\mathrm{CO}_{2}$ consumption.

On the other hand, if discharges were to drop sharply, solute fluxes would also be expected to decrease. As an example, the seaward total dissolved solids flux from the Huanghe (Yellow) River, China has decreased by more than half over the last approximately 40 years because of a sharp decrease in water discharge in the lower reaches of the river (Chen et al., 2005). Diversions, irrigation and reservoir use are primarily responsible for the decrease in water discharge, and despite an increase of $\sim 5$ to $10 \mathrm{mg} / \mathrm{l} / \mathrm{year}$ in total dissolved solids in the middle and lower reaches of the river, there has been an overall decrease in solute flux (Chen et al., 2005). Climate change models predict that flows in the southwestern United States and other dry areas are likely to decrease by 10 to $40 \%$ by $2090-2099$ relative to $1980-1999$ in a 

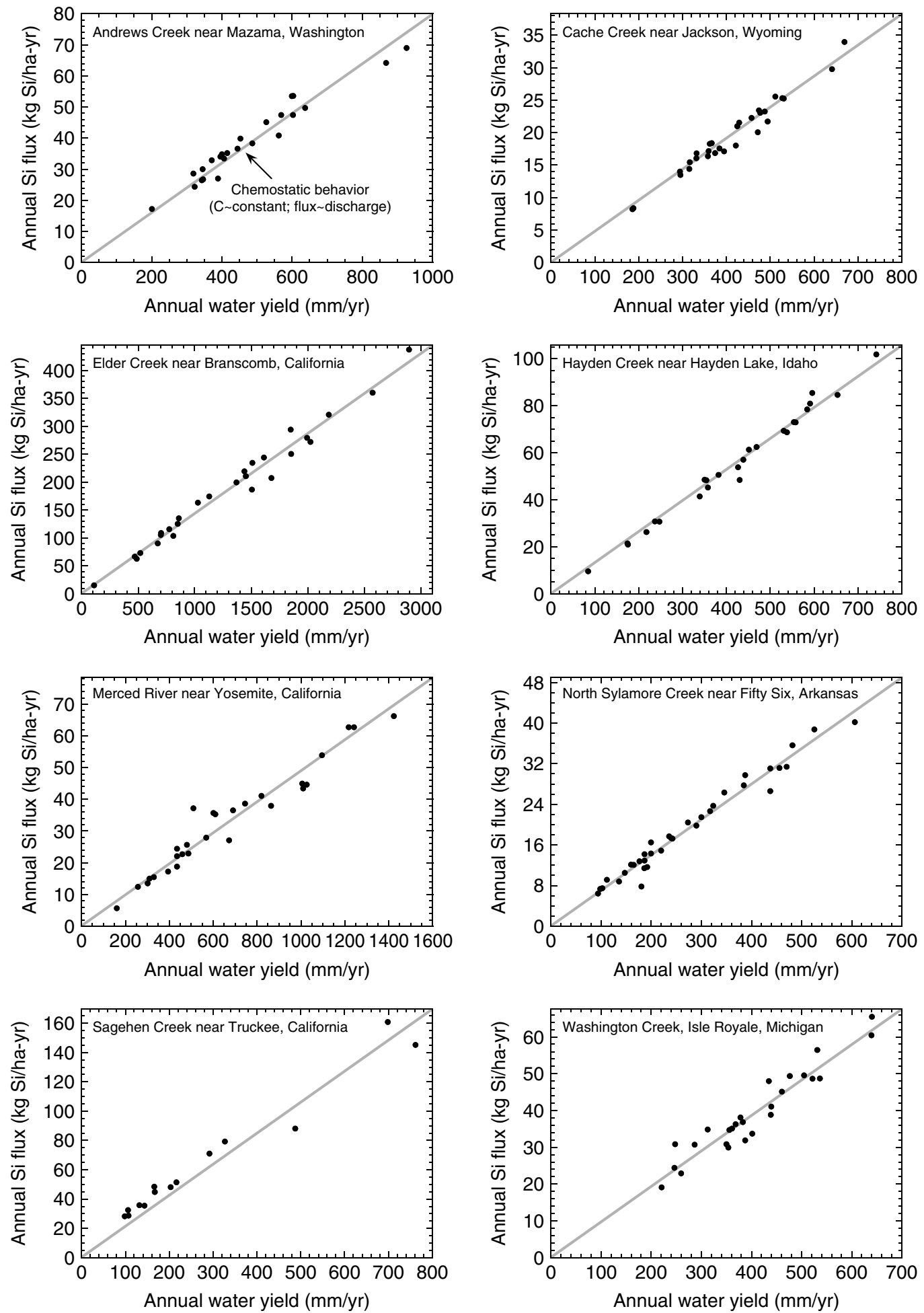

Figure 6. Annual silica fluxes in streamflow as a function of annual water yield for the eight Hydrological Benchmark Network streams shown in Figures 1 and 3. The diagonal grey line indicates solute fluxes proportional to discharge (i.e. constant concentration).

scenario in which global average temperatures increase by $2.8{ }^{\circ} \mathrm{C}$ over the same period (IPCC, Core Writing Team, 2007). One would expect solute flux of the major base cations and silica from streams and rivers in these regions to decrease by an amount that is approximately proportional to the decrease in flows.

The stability of concentrations of weathering products across a wide range of flow regimes may be important both for the health of individual organisms and for the diversity of aquatic ecosystems. At an organismal level, mortality from acidification-induced aluminum toxicity is closely linked to decreases in alkalinity and base cation concentrations (Jeffries et al., 1992; Thornton and Dise, 1998). Metals and other contaminants are more toxic to juvenile fish in waters with lower hardness, which as noted above, is usually equal to sum of the concentration 
of $\mathrm{Ca}$ and $\mathrm{Mg}$ (e.g. Hall, 1991). The greater the stability of base cation concentrations across a wide range of flows, the smaller the likelihood that toxicity thresholds will be crossed during hydrological extremes because concentrations will not drop precipitously when flows increase.

At a species to community level, site-to-site comparisons reveal that benthic macroinvertebrate and diatom species diversity is a function of total dissolved solid concentration, conductivity or salinity in some streams, lakes and fjords (Metzeling, 1993, Ryves et al., 2004). Solute fluxes, especially the amount of Si relative to other potentially limiting nutrients, can be a predictor of phytoplankton blooms and diatom growth (LePape et al., 1996; Grenz et al., 2000). Si concentrations relative to concentrations of $\mathrm{Fe}, \mathrm{N}$ and $\mathrm{P}$ strongly control diatom nutrient uptake and growth rates. Increased $\mathrm{N}$ and $\mathrm{P}$ concentrations relative to $\mathrm{Si}$ concentrations and decreased $\mathrm{Si}$ flux due to river regulation have shifted ecosystems dominated by siliceous phytoplankton or diatoms to those dominated by non-siliceous algae or flagellate communities (e.g. Officer and Ryther, 1980; Egge and Aksnes, 1992; Turner et al., 1998; Billen and Garnier, 2007). Oceanic Si limitations have been seen in the eastern equatorial Pacific and North Atlantic as well as in coastal communities that have experienced eutrophication problems due to increased $\mathrm{N}$ and/or P loads relative to Si loads (Ragueneau et al., 2000). Furthermore, rare taxa are more sensitive to changes in salinity than common taxa in siteto-site comparisons (Metzeling, 1993). Species that are more tolerant to salinity variations may be able to disperse widely into different rivers feeding an estuary or coastal region and negatively affect native populations, which may be adapted to the narrow range of concentrations seen in their particular chemostatic catchment (Bringolf et al., 2005). Therefore, the chemostatic behavior of catchments may enhance hydrochemical stability across a wide range of flows and thus promote biodiversity, but also suggests that streams subject to anthropogenic salinity variations or estuarine influences are more vulnerable to invasive species.

\section{CONCLUSIONS}

Concentrations of weathering-derived solutes vary little with discharge for 59 USGS HBN streams, indicating that these catchments exhibit nearly chemostatic behaviour. Concentrations vary by only a factor of 3 to 20 as discharge varies by several orders of magnitude, and annual mean concentrations are similarly insensitive to changes in annual water yield. Concentrations of the major base cations and silica typically exhibit power-law relationships with discharge, with small negative exponents. Broad qualitative lithologic differences, such as the presence or absence of volcanics or carbonates, are associated with statistically significant differences in the power-law concentration-discharge slope among different sites. Other site characteristics such as area, low temperature and average annual runoff are significantly rank-correlated with site-to-site variations in concentration-discharge slopes for some solutes, but the predictive power of site characteristics to quantify concentration-discharge slopes is limited. The narrow range of concentration variability with discharge implies that rates of solute production and mobilization must be nearly proportional to water fluxes. Because concentrations remain nearly constant across wide ranges in discharge, solute yield from catchments (and, at continental scale, alkalinity fluxes to the oceans) are predominantly determined by water yield.

It is difficult to find simple generalizable models that accurately represent the typical form of the concentration-discharge relationship, that are internally consistent, and that make plausible assumptions about catchment behaviour. A simple 'bucket' model cannot reproduce the observed concentration-discharge behaviour. The Hubbard Brook 'working model' can fit the observations, but the required best-fit 'rainfall' concentrations are much higher than observed concentrations, suggesting that key physical or chemical processes are not captured by the model. A Langbein-Dawdy chemical reaction model that assumes that reaction rates vary with distance from equilibrium can also fit the observed concentration-discharge relationships, but requires relatively high input concentrations (and therefore likely requires an important role for soil water) and assumes that no mixing of waters of different ages can occur. Finally, a new chemical and mixing model can explain the observed power-law relationships between concentration and discharge in terms of depth profiles of porosity, characteristic pore size and hydraulic conductivity in the catchment. In this model, changes in discharge correspond to changes in the depth of saturation in the subsurface. These in turn alter solute fluxes by altering the reactive wetted surface area. The assumptions of this new model should be tested at a subset of the HBN sites. An internally consistent model of hydrology, chemical weathering and transport is needed to explain the power-law concentration-discharge relationships that are observed across hydrochemically diverse catchments.

\section{ACKNOWLEDGEMENTS}

We thank Tom Meixner, Madeline Solomon, Steve Sebestyen, Jake Peters and Kathleen Lohse for their helpful discussions, and thank the 2003 Sagehen Watershed Symposium for stimulating the collaboration that led to this work. This work was supported by National Science Foundation (NSF) grant EAR-0125550, the Miller Institute for Basic Research in Science and an NSF Graduate Research Fellowship.

\section{APPENDIX}

Here we develop the new permeability-porosity-aperture model, briefly discussed in the main text, in which 
chemical weathering and hydrological mixing jointly control the relationship between solute concentrations and water fluxes.

First, we assume that permeability $(k,[\mathrm{~m} / \mathrm{s}])$, porosity $(\phi$, [dimensionless] $)$ and average pore aperture or width $(p,[\mathrm{~m}])$ all decrease exponentially with depth $(z,[\mathrm{~m}])$ from their values at the soil surface $\left(k_{o}, \phi_{\mathrm{o}}\right.$ and $p_{o}$, respectively):

$$
\begin{aligned}
& k=k_{o} e^{-z / \lambda_{k}} \\
& \phi=\phi_{o} e^{-z / \lambda_{\phi}} \\
& p=p_{o} e^{-z / \lambda_{p}}
\end{aligned}
$$

The rates at which these variables decrease with depth, as expressed by the e-folding distances $\left(\lambda_{k}, \lambda_{\phi}, \lambda_{p}\right.$ all $[\mathrm{m}])$, do not need to be equal to one another. Permeability and porosity are known to decrease roughly exponentially with depth at many sites. An exponential decrease in aperture with depth is less well characterized, but this assumption is plausible and testable. Invoking Darcy's law with an approximately constant head gradient along the hillslope, and using Equation A1, one can express specific discharge $(q,[\mathrm{~m} / \mathrm{s}])$ in a similar manner as an exponential function that varies as permeability decreases with depth:

$$
q=q_{o} e^{-z / \lambda_{k}}
$$

where $q_{o}$ is a reference discharge that equals $k_{o}$ times the hillslope gradient. Thus water discharge $\left(Q_{w},\left[\mathrm{~m}^{2} / \mathrm{s}\right]\right)$ per unit hillslope width can be calculated as:

$$
Q_{w}=\int_{z}^{\infty} q d z=\lambda_{k} q_{o} e^{-z / \lambda_{k}}
$$

One can also assume that water discharge is proportional to effective precipitation inputs:

$$
Q_{w}=R x
$$

where $R[\mathrm{~m} / \mathrm{s}]$ is the effective precipitation rate and $x$ $[\mathrm{m}]$ is distance from the hill crest to any point along the hillslope. By setting Equations (A5a) and (A5b) equal to one another, one can solve for depth of the hydrologically active region (i.e. soil and bedrock) as a function of distance along the hillslope:

$$
z(x)=-\lambda_{k} \ln \left(\frac{R x}{\lambda_{k} q_{o}}\right)
$$

Equation A6 assumes that effective precipitation is spatially uniform along the hillslope and that flow originating near the divide and near the stream (i.e. in the non-linear portions of the hillslope) is negligible, and thus that the approximation of a constant hillslope gradient in Equation A4 is valid.

We can also define the solute flux per unit hillslope width $\left(Q_{s},\left[\mathrm{~mol} \mathrm{~m} \mathrm{~m}^{-1} \mathrm{~s}^{-1}\right]\right)$ so that it is proportional to the reactive surface area per unit land area, $A_{*}$ [dimensionless]. Pore volume is the product of porosity and total volume $\left(V,\left[\mathrm{~m}^{3}\right]\right)$, and reactive surface area per unit volume of pores and medium can be defined as

$$
\begin{aligned}
& \text { surf ace area } /(\text { volume of pores }+ \text { medium }) \\
& \quad=\frac{V \phi \gamma}{p V}=\frac{\phi \gamma}{p}
\end{aligned}
$$

where $\gamma$ [dimensionless] is a shape factor that is assumed to be constant with depth. We then integrate to get reactive surface area per unit land area, $A_{*}$ :

$$
\begin{aligned}
A_{*} & =\int_{z}^{\infty} \gamma \frac{\phi}{p}=\int_{z}^{\infty} \gamma \frac{\phi_{o}}{p_{o}} e^{-z\left(1 / \lambda_{\phi}-1 / \lambda_{p}\right)} \\
& =\frac{\gamma \phi_{o}}{p_{o}\left(1 / \lambda_{\phi}-1 / \lambda_{p}\right)} e^{-z\left(1 / \lambda_{\phi}-1 / \lambda_{p}\right)}
\end{aligned}
$$

Note that there is a larger wetted reactive surface area per unit land area, $A_{*}$, at higher flow rates in this model as a result of the relationship between $z$ and $R$ (Equation (A6)). For a surface dissolution reaction in which secondary and back-reactions can be ignored, solute flux per unit hillslope width $\left(Q_{s}\right)$ is the product of the reaction constant, $k_{R}\left[\mathrm{~mol} \mathrm{~m}^{-2} \mathrm{~s}^{-1}\right.$ ], and the reactive surface area per unit land area, $A_{*}$, integrated along the linear segment of the hillslope from the base $(x=0)$ to near the ridge $(x=L)$ using the relationships derived in Equations (A6) and (A8):

$$
\begin{aligned}
Q_{s}= & \int_{0}^{L} k_{R} A_{*} d x=\int_{0}^{L} \frac{k_{R} \gamma \phi_{o}}{p_{o}\left(1 / \lambda_{\phi}-1 / \lambda_{p}\right)} \\
& e^{\left(\lambda_{k} / \lambda_{\phi}-\lambda_{k} / \lambda_{p}\right) \ln \left(\frac{R x}{\lambda_{k} q_{o}}\right) d x} \\
= & \int_{0}^{L} \frac{k_{R} \gamma \phi_{o}}{p_{o}\left(1 / \lambda_{\phi}-1 / \lambda_{p}\right)} \\
& \left(\frac{R x}{\lambda_{k} q_{o}}\right)\left(\frac{\left.\lambda_{k} / \lambda_{\phi}-\lambda_{k} / \lambda_{p}\right)}{p_{R}\left(1 / \lambda_{\phi}-1 / \lambda_{p}\right)}\left(\frac{1}{1+\lambda_{k} / \lambda_{\phi}-\lambda_{k} / \lambda_{p}}\right)\right. \\
& \left.\left(\frac{\lambda_{k} q_{o}}{R}\right)\left(\frac{R x}{\lambda_{k} q_{o}}\right)\right|_{0} ^{\left(\lambda_{k} / \lambda_{\phi}-\lambda_{k} / \lambda_{p}+1\right)} \\
= & \frac{L k_{R} \gamma \phi_{o}}{p_{o}\left(1 / \lambda_{\phi}-1 / \lambda_{p}\right)\left(1+\lambda_{k} / \lambda_{\phi}-\lambda_{k} / \lambda_{p}\right)} \\
& \left(\frac{R L}{\lambda_{k} q_{o}}\right)\left(\lambda_{k} / \lambda_{\phi}-\lambda_{k} / \lambda_{p}\right)
\end{aligned}
$$

The volume-weighted mean concentration in the water flux $\left(\bar{C},\left[\mathrm{~mol} / \mathrm{m}^{3}\right]\right)$ is equal to the ratio of the solute flux (Equation A9) to the water flux $(=R L)$, both expressed per unit hillslope width:

$$
\bar{C}=\frac{Q_{s}}{Q_{w}}=\frac{\int_{0}^{L} k_{R} A_{*} d x}{Q_{w}}
$$




$$
\begin{aligned}
= & \frac{L k_{R} \gamma \phi_{o}}{p_{o}\left(1 / \lambda_{\phi}-1 / \lambda_{p}\right)\left(1+\lambda_{k} / \lambda_{\phi}-\lambda_{k} / \lambda_{p}\right)} \\
& \left(\frac{1}{\lambda_{k} q_{o}}\right)^{\left(\lambda_{k} / \lambda_{\phi}-\lambda_{k} / \lambda_{p}\right)}{ }_{(R L)}\left(\lambda_{k} / \lambda_{\phi}-\lambda_{k} / \lambda_{p}-1\right) \\
= & a_{o} Q_{w}^{b_{0}}
\end{aligned}
$$

A power-law concentration-discharge relationship can thus be expressed for a one-dimensional hillslope, with the constant $a_{o}\left[\mathrm{~mol} \cdot \mathrm{s}\left(\frac{\lambda_{k}}{\lambda_{\phi}}-\frac{\lambda_{k}}{\lambda_{p}}-1\right) /\right.$ $\left.\mathrm{m}\left(\frac{2 \lambda_{k}}{\lambda_{\phi}}-\frac{2 \lambda_{k}}{\lambda_{p}}+1\right)\right]$ equal to all of the other constants

before the $R L$ term, and the power-law exponent $b_{0}$ [dimensionless] equal to:

$$
b_{0}=\left(\lambda_{k} / \lambda_{\phi}-\lambda_{k} / \lambda_{p}-1\right)
$$

Furthermore, storage $(S,[\mathrm{~m}])$ can be defined as the integral of porosity over total depth:

$$
S=\int_{z}^{\infty} \phi=\lambda_{\phi} \phi_{o} e^{-z / \lambda_{\phi}}
$$

By combining Equations A5a and A12, one can see that discharge $\left(Q_{w}\right)$ varies as a power function of storage:

$$
Q_{w} / Q_{o}=\left(S / S_{o}\right)^{b_{1}}
$$

where $Q_{o}$ and $S_{o}$ are reference values of discharge and storage, such that $Q_{w}=Q_{o}$ at $S=S_{o}$, and the power-law exponent, $b_{1}$ [dimensionless] is:

$$
b_{1}=\frac{\lambda_{\phi}}{\lambda_{k}} \text {. }
$$

The value of $b_{1}$ can be determined from recession analysis, because Equation A13a implies that a plot of $-\mathrm{d} Q_{w} / \mathrm{d} t$ as a function of $Q_{w}$ should have a $\log -\log$ slope of $2-\left(1 / b_{1}\right)$, derived during periods when both evapotranspiration and precipitation are small relative to discharge (e.g. during rain-free nights) (Kirchner, 2009).

\section{REFERENCES}

Anderson SP, Dietrich WE. 2001. Chemical weathering and runoff chemistry in a steep headwater catchment. Hydrological Processes 15 : $1791-1815$.

Billen G, Garnier J. 2007. River basin nutrient delivery to the coastal sea: Assessing its potential to sustain new production of non-siliceous algae. Marine Chemistry 106: 148-160.

Brantley SL. 1992. Kinetics of dissolution and precipitation-experimental and field results. In Proceedings of the 7th Water-Rock Interaction Symposium-Park City, UT, vol. 1, Kharak YF, Maest AS (eds). AA Balkema: Rotterdam; 3-6.

Brantley SL. 2004. Reaction kinetics of primary rock-forming minerals under ambient conditions. In Treatise on Geochemistry: Surface and Ground Water, Weathering, and Soils, Drever JI, Holland HD, Turekian KK (eds). Elsevier Pergamon: Amsterdam; 73-117.

Bricker OP. 1968. Cations and silica in natural waters: control by silicate minerals. In Geochemistry, Precipitation, Evaporation Soil-Moisture,
Hydrometry-General Assembly of Bern, Reports and Discussions, IAHS Publ. 78, IAHS: Bern; 110-119.

Bringolf RB, Kwak TJ, Cope WG, Larimore MS. 2005. Salinity tolerance of flathead catfish: implications for dispersal of introduced populations. Transactions of the American Fisheries Society 134: 927-936.

Buttle JM. 1994. Isotope hydrograph separations and rapid delivery of pre-event water from drainage basins. Progress in Physical Geography 18: $16-41$.

Chanat JG, Rice KC, Hornberger GM. 2002. Consistency of patterns in concentration-discharge plots. Water Resources Research 38: 22. DOI: 10.1029/2001WR000971.

Chen J, Wang F, Meybeck M, He D, Xia X, Zhang L. 2005. Spatial and temporal analysis of water chemistry records (1958-2000) in the Huanghe (Yellow River) basin. Global Biogeochemical Cycles 19: GB3016. DOI: 10.1029/2004GB002325.

Clark ML, Eddy-Miller CA, Mast MA. 2000. Environmental Characteristics and Water Quality of Hydrologic Benchmark Network Stations in the West-Central United States, 1963-95., USGS Circular 1173-C. USGS: Reston; 115.

Clow DW, Drever JI. 1996. Weathering rates as a function of flow through an alpine soil. Chemical Geology 132: 131-141.

Drever JI. 1994. The Effect of Land Plants on Weathering Rates of Silicate Minerals. Geochimica Et Cosmochimica Acta 58: 2325-2332.

Drever JI, Clow DW. Weathering Rates in Catchments. In Chemical Weathering Rates of Silicate Minerals,1995. 463-483.

Egge JK, Aksnes DL. 1992. Silicate as Regulating Nutrient in Phytoplankton Competition. Marine Ecology-Progress Series 83: 281-289.

Evans C, Davies TD. 1998. Causes of concentration/discharge hysteresis and its potential as a tool for analysis of episode hydrochemistry. Water Resources Research 34: 129-137.

Evans C, Davies TD, Murdoch PS. 1999. Component flow processes at four streams in the Catskill Mountains, New York, analysed using episodic concentration/discharge relationships. Hydrological Processes 13: $563-575$.

Godderis Y, Francois LM, Probst A, Schott J, Moncoulon D, Labat D, Viville D. 2006. Modelling weathering processes at the catchment scale: the WITCH numerical model. Geochimica Et Cosmochimica Acta 70: $1128-1147$

Grenz C, Cloern JE, Hager SW, Cole BE. 2000. Dynamics of nutrient cycling and related benthic nutrient and oxygen fluxes during a spring phytoplankton bloom in South San Francisco Bay (USA). Marine Ecology-Progress Series 197: 67-80.

Hall FR. 1970. Dissolved solids-discharge relationships 1. Mixing models. Water Resources Research 6: $845-850$.

Hall FR. 1971. Dissolved solids-discharge relationships 2. Applications to field data. Water Resources Research 7: 591-601.

Hall LW. 1991. A Synthesis of Water-Quality and Contaminants Data on Early Life Stages of Striped Bass, Morone-Saxatilis. Reviews in Aquatic Sciences 4: 261-288.

Hem JD. 1948. Fluctuations in concentration of dissolved solids of some southwestern streams. Transactions, American Geophysical Union 29 $80-84$

Hem JD. 1985. Study and Interpretation of the Chemical Characteristics of Natural Water. 3rd edn, USGS Water Supply Paper 2254. USGS Alexandria, VA; 263

Hornberger GM, Scanlon TM, Raffensberger JP. 2001. Modelling transport of dissolved silica in a forested headwater catchment: the effect of hydrological and chemical time scales on hysteresis in the concentration-discharge relationship. Hydrological Processes 15: 2029-2038. DOI: 10.1002/hyp.254.

House WA, Warwick MS. 1998. Hysteresis of the solute concentration/discharge relationship in rivers during storms. Water Research 32 2279-2290.

IPCC, Core Writing Team. 2007. Climate Change 2007: Synthesis Report. Contribution of Working Groups I, II and III to the Fourth Assessment Report of the Intergovernmental Panel on Climate Change. Pachauri RK and Reisinger A (eds). IPCC: Geneva, Switzerland; 104.

Jeffries DS, Lam DCL, Wong I, Bloxam RM. 1992. The predicted effect of $\mathrm{SO}_{2}$ emission controls on the water-quality of eastern Canadian lakes. Environmental Monitoring and Assessment 23: 99-113.

Johnson DW, Susfalk RB, Dahlgren RA, Caldwell TG, Miller WW. 2001. Nutrient fluxes in a snow-dominated, semi-arid forest: spatial and temporal patterns. Biogeochemistry 55: 219-245.

Johnson NM, Likens GE, Bormann FH, Fisher DW, Pierce RS. 1969. A working model for the variation in stream water chemistry at the Hubbard Brook Experimental Forest, New Hampshire. Water Resources Research 5: 1353-1363. 
Kirchner JW. 2009. Catchments as simple dynamical systems: catchment characterization, rainfall-runoff modeling, and doing hydrology backwards. Water Resources Research 45: W02429. DOI:10.1029/2008WR006912.

Langbein WB, Dawdy DR. 1964. Occurrence of dissolved solids in surface waters in the United States., USGS Prof. Paper 501-D. USGS: Washington, DC; D115-D117.

Langmuir D. 1997. Aqueous Environmental Geochemistry. Prentice Hall: Upper Saddle River, NJ; 600.

Leopold LB. 1962. A national network of hydrologic bench marks, USGS Circular 460-B. USGS: Washington, DC; 4.

LePape O, Del Amo Y, Menesguen A, Aminot A, Quequiner B, Treguer P. 1996. Resistance of a coastal ecosystem to increasing eutrophic conditions: The Bay of Brest (France), a semi-enclosed zone of Western Europe. Continental Shelf Research 16: 1885-1907.

Mast MA, Clow DW. 2000. Environmental Characteristics and Water Quality of Hydrologic Benchmark Network Stations in the Western United States, 1963-1995, USGS Circular 1173-D. USGS: Reston; 114.

Mast MA, Turk JT. 1999a. Environmental Characteristics and Water Quality of Hydrologic Benchmark Network Stations in the Eastern United States, 1963-1995, USGS Circular 1173-A. USGS: Denver; 158.

Mast MA, Turk JT. 1999b. Environmental Characteristics and Water Quality of Hydrologic Benchmark Network Stations in the Midwestern United States, 1963-1995, USGS Circular 1173-B. USGS: Denver; 130 .

McGuire KJ, McDonnell JJ. 2006. A review and evaluation of catchment transit time modeling. Journal of Hydrology 330: 543-563.

McSween HY, Richardson SM, Uhle ME. 2003. Geochemistry: Pathways and Processes. Columbia University Press: New York; 363.

Metzeling L. 1993. Benthic macroinvertebrate community structure in streams of different salinities. Australian Journal of Marine and Freshwater Research 44: 335-351.

Murdoch PS, Stoddard JL. 1992. The role of nitrate in the acidification of streams in the Catskill Mountains of New York. Water Resources Research 28: 2707-2720.

Nordstrom DK. 2004. Modeling low-temperature geochemical processes. In Treatise on Geochemistry: Surface and Ground Water, Weathering, and Soils, Drever JI, Holland HD, Turekian KK (eds). Elsevier Pergamon: Amsterdam; 37-72.

Officer CB, Ryther JH. 1980. The Possible Importance of Silicon in Marine Eutrophication. Marine Ecology-Progress Series 3: 83-91.

Oliva P, Viers J, Dupre B, Fortune JP, Martin F, Braun JJ, Nahon D, Robain H. 1999. The effect of organic matter on chemical weathering: Study of a small tropical watershed: Nsimi-Zoetele site, Cameroon. Geochimica Et Cosmochimica Acta 63: 4013-4035.

Parkhurst DL, Appelo CAJ. 1999. User's Guide for PHREEQC (version 2)-A Computer Program for Speciation, Batch-Reaction, One-
Dimensional Transport, and Inverse Geochemical Calculations, WRI Report 99-4529. USGS: Denver; 312.

Ragueneau O, Treguer P, Leynaert A, Anderson RF, Brzezinski MA, DeMaster DJ, Dugdale RC, Dymond J, Fischer G, Francois R, Heinze C, Maier-Reimer E, Martin-Jezequel V, Nelson DM, Queguiner B. 2000. A review of the Si cycle in the modem ocean: recent progress and missing gaps in the application of biogenic opal as a paleoproductivity proxy. Global and Planetary Change 26: 317-365.

Raymond PA, Cole JJ. 2003. Increase in the export of alkalinity from North America's largest river. Science 301: 88-91.

Ryves DB, Clarke AL, Appleby PG, Amsinck SL, Jeppesen E, Landkildehus F, Anderson NJ. 2004. Reconstructing the salinity and environment of the Limfjord and Vejlerne Nature Reserve, Denmark, using a diatom model for brackish lakes and fjords. Canadian Journal of Fisheries and Aquatic Sciences 61: 1988-2006. DOI: 10.1139/F04127.

Schnoor JL. 1990. Kinetics of chemical weathering: a comparison of laboratory and field weathering rates. In Aquatic Chemical Kinetics: Reaction Rates of Processes in Natural Waters, Stumm W (ed). John Wiley \& Sons: New York; 475-504

Thornton GJP, Dise NB. 1998. The influence of catchment characteristics, agricultural activities and atmospheric deposition on the chemistry of small streams in the English Lake District. Science of the Total Environment 216: 63-75.

Turner RE, Qureshi N, Rabalais NN, Dortch Q, Justic D, Shaw RF, Cope J. 1998. Fluctuating silicate: nitrate ratios and coastal plankton food webs. Proceedings of the National Academy of Sciences of the United States of America 95: 13048-13051.

Waylen MJ. 1979. Chemical weathering in a drainage basin underlain by old red sandstone. Earth Surface Processes 4: 167-178.

Walling DE, Webb BW. 1986. Solutes in river systems. In Solute Processes, Trudgill ST (ed). John Wiley \& Sons: Chichester; 251-327. White AF, Blum AE, Schulz MS, Bullen TD, Harden JW, Peterson ML 1996. Chemical weathering rates of a soil chronosequence on granitic alluvium: I. Quantification of mineralogical and surface area changes and calculation of primary silicate reaction rates. Geochimica et Cosmochimica Acta 60: 2533-2550.

Wilde FD, Radtke DB, Gibs J and Iwatsubo RT (eds). 1998. National Field Manual for the Collection of Water-Quality Data, vol. 9. USGS: Denver.

Zakharova EA, Pokrovsky OS, Dupre B, Zaslavskaya MB. 2005. Chemical weathering of silicate rocks in Aldan Shield and Baikal Uplift: insights from long-term seasonal measurements of solute fluxes in rivers. Chemical Geology 214: 223-248.

Zar JH. 1984. Biostatistical Analysis, 2nd edn. Prentice Hall: Englewood Cliffs, NJ; 718. 